Linköping University Medical Dissertations No 1540

\title{
Regulatory programs controlling proliferation during Drosophila nervous system development
}

Erika Gunnar

Department of Clinical and Experimental Medicine Faculty of Medicine and Health Sciences

Linköping University, Sweden 2017

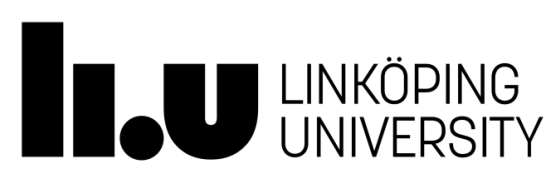


Back cover: Confocal image of cells expressing eg-Gal4/UAS-GFP in a wild type, showing the cells generated from NB3-3A.

Front cover: Confocal image of cells expressing eg-Gal4/UAS-GFP in a seq mutant, showing over-proliferation in NB3-3A.

Published articles have been re-printed with permission from the copyright holders.

Printed by LiU-Tryck, Linköping, Sweden 2017

ISBN: 978-91-7685-681-9

ISSN: 0345-0082 
Somewhere, something incredible is waiting to be known Sharon Begley (1977) 


\section{Supervisor}

\section{Stefan Thor}

Department of Clinical and Experimental Medicine Faculty of Medicine and Health Sciences

Linköping University, Sweden

\section{Co-Supervisor}

\section{Jan-Ingvar Jönsson}

Department of Clinical and Experimental Medicine

Faculty of Medicine and Health Sciences

Linköping University, Sweden

\section{Faculty Opponent}

\section{Udo Häcker}

Department of Experimental Medical Science

Faculty of Medicine

Lund University, Sweden 


\section{Abstract}

The central nervous system (CNS) is the most complex organ in the body, responsible for complex functions, including thinking, reasoning and memory. The CNS contains cells of many different types, often generated in vast numbers. Hence, CNS development requires precise genetic control of both cell fate and of cell proliferation, to generate the right number of cells, with the proper identity, and in the proper location. The cells also need to make connections with each other for correct signaling and function. This complexity evokes the question of how this is regulated. How does the stem cells, responsible for building the CNS, know how many times to divide, and how does the daughters know which identity to acquire and in which location they shall end up? During Drosophila melanogaster development, the neuroblasts (NBs) are responsible for generating the CNS. In each hemisegment, every NB is unique in identity, and generates a predetermined number of daughters with specific identities. The lineages of different NBs vary in size, but are always the same for each specific NB, and the division modes of each NBs is hence stereotyped. Most NBs start dividing by renewing themselves while generating daughters that will in turn divide once to generate two neurons and/or glia (denoted type I mode). Many, maybe all, NBs later switch to generating daughters that will differentiate directly into a neuron or glia (denoted type 0 mode). This type $\mathrm{I}>0$ switch occurs at different time-points during lineage progression, and influences the total numbers of cells generated from a single NB.

The work presented in this thesis aimed at investigating the genetic regulation of proliferation, with particular focus on the type I $>0$ switch. In the first project, the implication of the Notch pathway on the type I $>0$ switch was studied. Mutants of the Notch pathway do not switch, and the results show that the Notch pathway regulates the switch by activation of several target genes, both regulators and cell cycle genes. One of the target genes, the $E$ ( $s p l$ )- $C$ genes, have been difficult to study due to functional redundancy. This study reveals that even though they can functionally compensate for each other, they have individual functions in different lineages. Regarding cell cycle genes, both Notch and E(spl)-C regulate several key cell cycle genes, and molecular analysis indicated that this regulation is direct. In the second project we studied the seq gene, previously identified in a genetic screen. We found that seq controls the type I $>0$ switch by regulating the key cell cycle genes, but also through interplay with the Notch pathway. Notch and seq stop proliferation, and in the third project we wanted to identify genes that drive proliferation. We found that there is battery of early NB genes, socalled early factors, which activate the cell cycle, and drive NB and daughter proliferation. These are gradually replaced by late regulators, and the interplay between early and late factors acts to achieve precise control of lineage progression.

The work presented here increases our understanding of how regulatory programs act to control the development of the CNS; to generate the right number of cells of different identities. These results demonstrate the importance of correct regulation of proliferation in both stem cells and daughters. Problems in this control can result in either an underdeveloped CNS or loss of control such as in cancer. Knowledge about these regulatory programs can contribute to the development of therapeutics against these diseases. 



\section{Populärvetenskaplig sammanfattning}

Det centrala nervsystemet (CNS) är kroppens mest komplexa organ. Det ansvarar för komplexa uppgifter såsom tänkande, medvetande och inlärning. CNS består av många olika celltyper som bildas i stort antal, och därmed finns en mångfald av olika celler med specifika funktioner. För att CNS ska bildas med rätt antal celler, med rätt identitet, och på rätt ställe krävs kontroll under utvecklingen. Problem i denna reglering kan leda till att CNS blir underutvecklat med kognitiva problem, eller att kontrollen över stamcellerna förloras och de börjar dela sig okontrollerat och cancer utvecklas. Hur regleras bildandet av CNS?

Jag har använt Drosophila melanogaster som modellsystem för att studera utvecklingen av CNS under embryonalutvecklingen. I varje hemisegment är varje enskild neuroblast (NB), stamcellerna i CNS, unik i sin identitet genom att de föds på samma ställe och genererar samma antal dotterceller i varje embryo. De flesta NBs börjar dela sig så att de förnyar sig själva och bildar en dottercell, och dottercellen i sin tur delar sig en gång och generar två nervceller och/eller gliaceller (typ I). Många NBs skiftar senare under utveckling till att dela sig så att de förnyar sig själva och bildar en nervcell/gliacell direkt (typ 0). Detta skifte i delningsmönster (typ I $>0$ ) kan ske vid olika tidpunkter för olika NBs, och påverkar antalet celler som bildas från varje enskild NB. Jag har studerat hur delningar av NBs och dotterceller, speciellt detta skifte, regleras genetiskt. I det första projektet studerades hur signalvägen Notch påverkar skiftet. Mutanter i Notch genomgår inte skiftet utan döttrarna fortsätter att dela sig och bildar fler celler än normalt. Resultaten visar att Notch reglerar skiftet genom att aktivera målgener och gener som styr celldelning. Målgenerna, tillhörande genkomplexet $E(s p l)-C$, har varit svåra att studera då de kan kompensera för varandras funktion, men i denna studie såg vi att de har individuella funktioner. I det andra projektet studerades en gen, sequoia, som tidigare identifierats för att fler celler bildas från en NB när genen muteras. Vi kunde se att denna gen förhindrar att skiftet sker genom att reglera samma gener som signalvägen Notch, men också genom att samverka med Notch. Både Notch och sequoia hindrar därmed celler från att dela sig, och i det tredje projektet ville vi identifiera gener som stimulerar celler att föröka sig. Vi fann att gener som uttrycks tidigt under utvecklingen i NBs stimulerar celler att dela sig, och att dessa successivt ersätts av gener som hindrar delningar. Dessa interagerar med varandra genom att reglera gener som styr celldelning, men även genom att reglera varandra. Detta säkerställer att NBs och deras döttrar delar sig rätt antal gånger och genererar rätt antal döttrar av varje identitet.

Arbetet presenterat i den här avhandlingen hjälper till att öka förståelsen för hur regulatoriska program verkar för att kontrollera utvecklingen av CNS, så att rätt antal celler av varje identitet bildas. Dessa resultat visar på betydelsen av korrekt reglering av förökningen hos både stamceller och deras döttrar. Problem i denna kontroll kan leda till antingen ett underutvecklat CNS eller överväxt av celler såsom i cancer, men även psykiatriska sjukdomar som depression. Kunskap om dessa regulatoriska program kan bidra till utvecklingen av läkemedel mot sjukdomarna. 



\section{Table of contents}

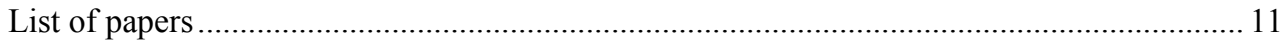

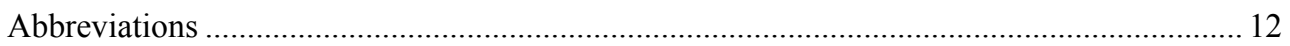

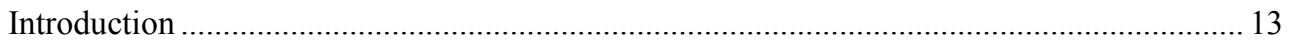

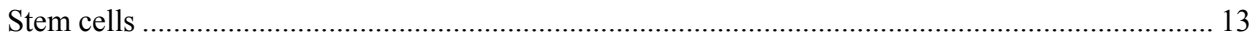

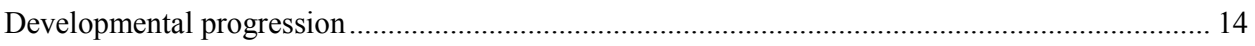

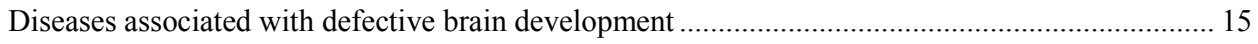

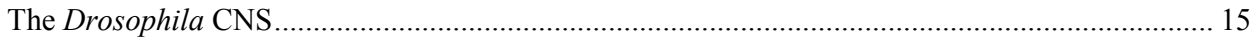

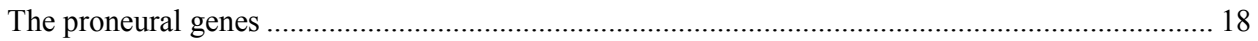

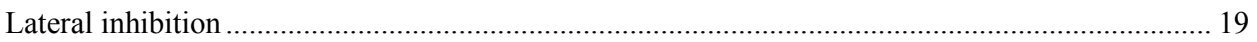

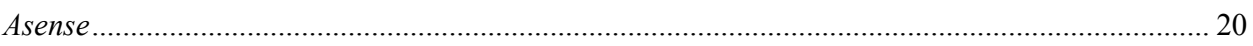

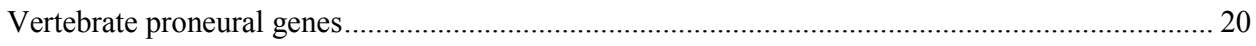

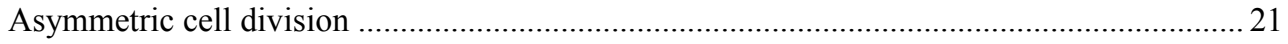

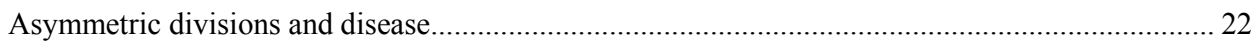

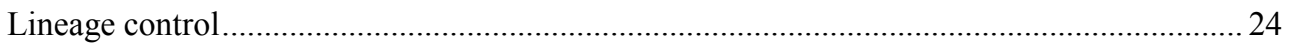

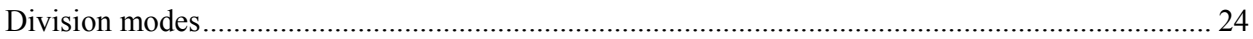

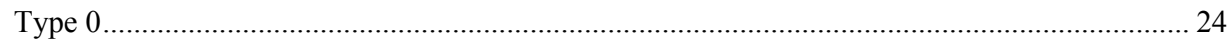

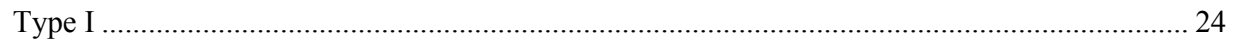

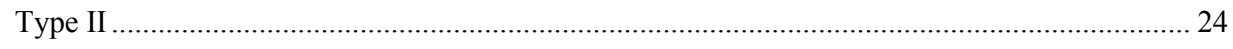

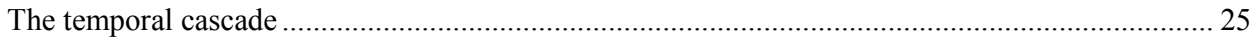

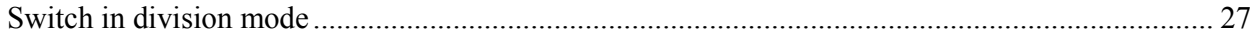

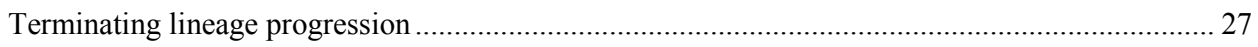

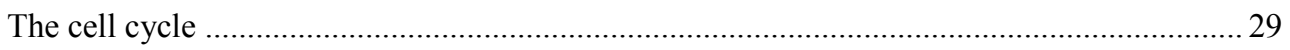

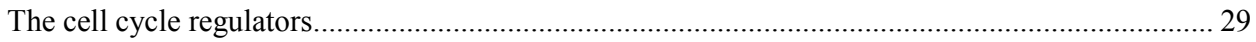

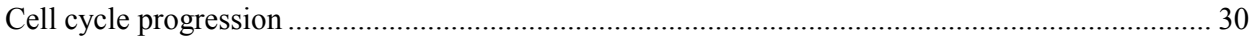

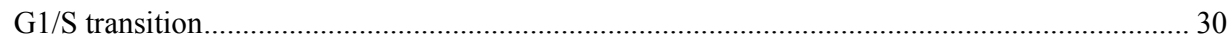

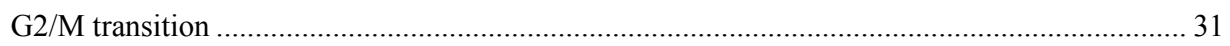

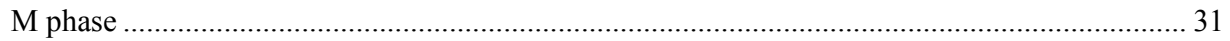

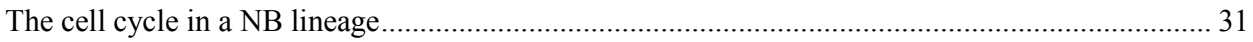

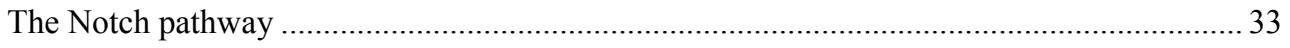

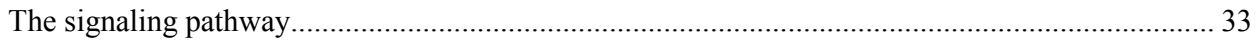

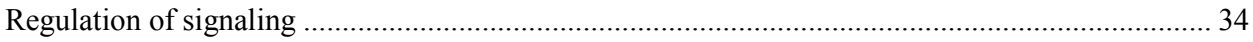

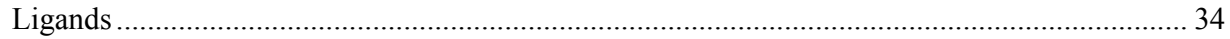

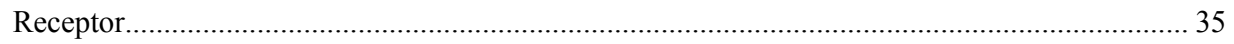

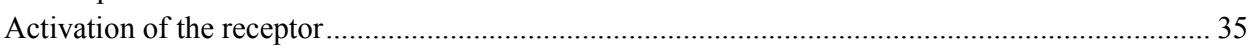

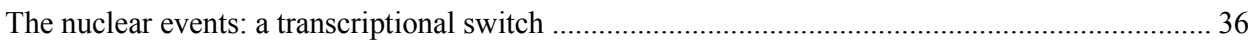

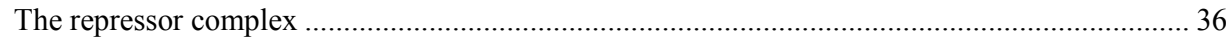

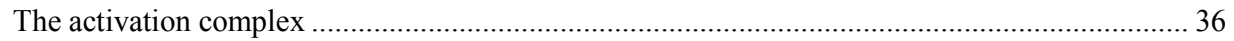

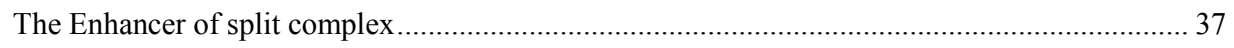

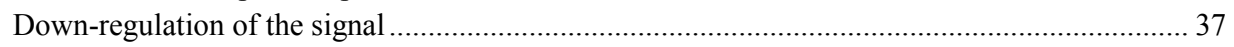

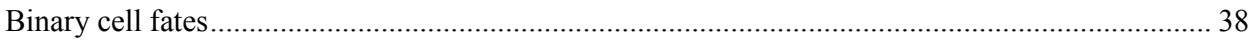

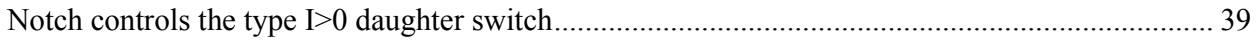

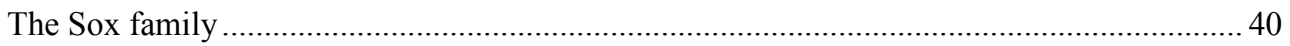

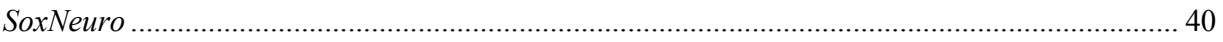

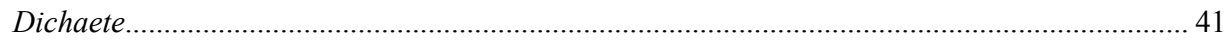

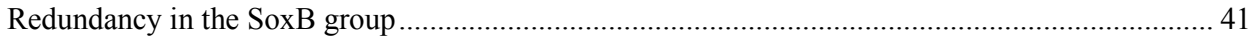




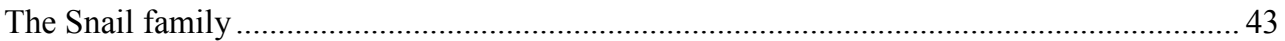

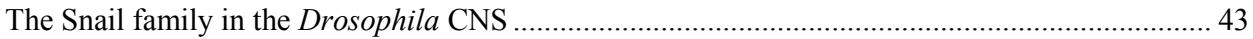

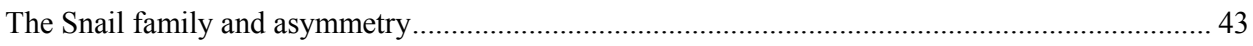

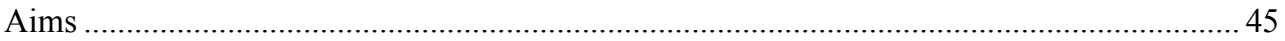

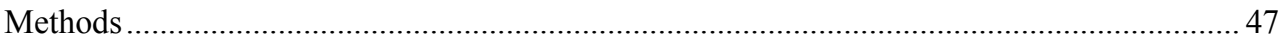

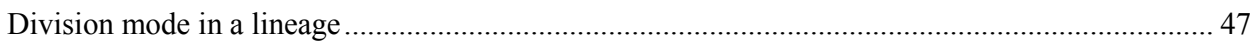

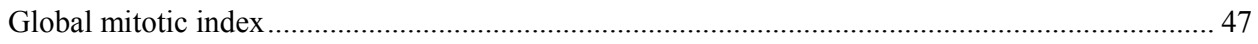

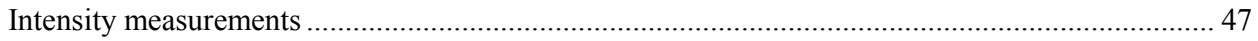

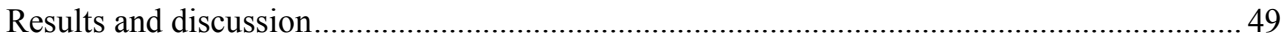

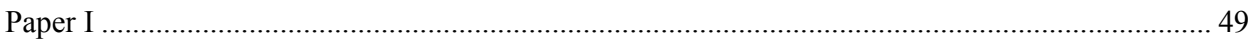

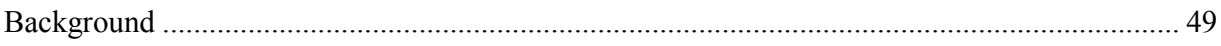

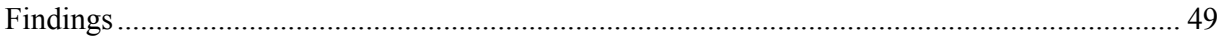

Conclusions ……

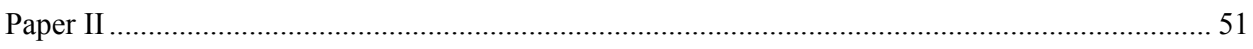

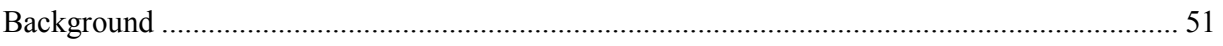

Findings

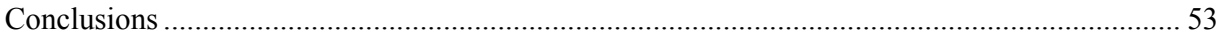

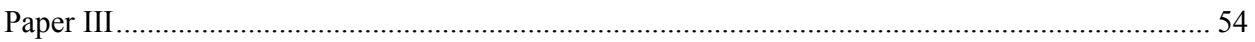

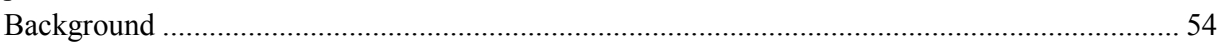

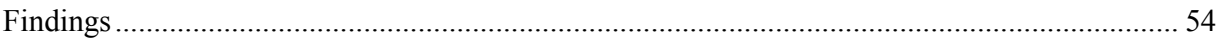

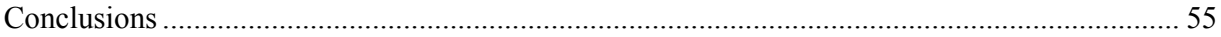

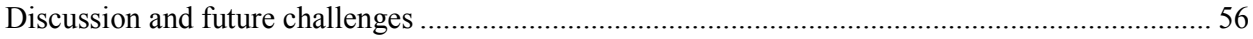

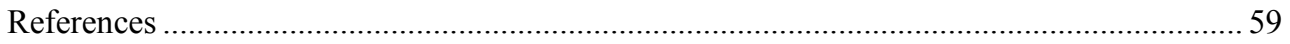

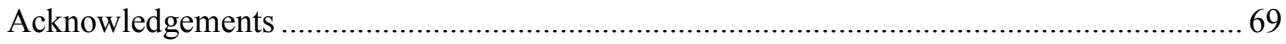




\section{List of papers}

This thesis is based on the following papers, which will be referred to by their roman numeral:

\section{Paper I}

Bivik, C., MacDonald, R., Gunnar, E., Mazouni, K., Schweisguth, F., Thor, S (2016).

Control of Neural Daughter Cell Proliferation by Multi-level Notch/Su(H)/E(spl)-HLH

Signaling. PLOS Genet., 12 (4).

\section{Paper II}

Gunnar, E., Bivik, C., Starkenberg, A., Thor, S (2016). sequoia controls the type I $>0$ daughter proliferation switch in the developing Drosophila nervous system. Development, Oct $15 ; 143(20): 3774-3784$.

\section{Paper III}

Bahrampous, S., Gunnar, E., Jönsson, C., Ekman, H., Thor, S (2016). Neural Lineage Progression Controlled by a Temporal Proliferation Program. Submitted. 


\section{Abbreviations}

AS-C Achaete-scute complex

AP Anterior-posterior

bHLH basic helix-loop-helix

CNS Central nervous system

DV Dorsal-ventral

E(spl)-C Enhancer of Split Complex

GMC Ganglion mother cell

HAT Histone acetylase

HDAC Histone deacetylase

INP Intermediate neural progenitor

NB Neuroblast

NEXT Notch extracellular truncation

NICD Notch intracellular domain

PNS Peripheral nervous system

PRDM Positive regulatory domain

SOP Sensory organ precursor

TF Transcription factor

VNC Ventral nerve cord 


\section{Introduction}

The development of a fertilized egg into an adult organism requires control and coordination in the generation of cell types, cell numbers and location of these cells. The central nervous system (CNS) is a complex organ, composed of many different cell types, and containing the greatest cellular diversity of any organ (Skeath and Thor 2003; Franco and Muller 2013). The human brain is estimated to contain around 100 billion neurons (Muotri and Gage 2006), and the major cell types are neurons and glia. Neurons are responsible for transmitting signals through electrical signals via connections to other cells, and glia cells myelinate and support neurons. These cell types can be further subdivided into many groups that together display a tremendous diversity in their morphology, connections and functions. Evolutionary, the size of the brain has expanded, but higher mammals also have folds (gyrations) that increases the area and this is thought to contribute to more advanced functions, such as learning, memory, consciousness, complex thoughts and reasoning (Franco and Muller 2013; Ghosh and Jessberger 2013; Paridaen and Huttner 2014).

\section{Stem cells}

How is development of such a complex organ as the CNS coordinated? The control of the number of cells, cell fate, location, timing and establishment of connections to other cells is a prerequisite for a functional organism. Disturbing any of these processes can result in symptoms ranging from cognitive impairments to an underdeveloped brain or cancer. It all starts with the stem cells at early embryonic development. Stem cells have the ability to selfrenew and generate new cells that can develop into specialized cells (Bongso and Lee 2005). The fertilized oocyte first generates three germ layers, and these contribute to different parts of the organism. The germ layers are ectoderm, mesoderm and endoderm, and the CNS is born from the ectoderm. The oocyte is totipotent, meaning it can generate cells of all three germ layers and create a new organism (Dang-Nguyen and Torres-Padilla 2015). As development progresses, stem cells get increasingly specialized and loose ability to create cells stepwise. Pluripotent stem cells have the ability to give rise to all the cells in the body but cannot generate a new organism, while multipotent stem cells have the ability to generate a more limited number of cell types (Gotz and Huttner 2005; Dang-Nguyen and TorresPadilla 2015). One important factor contributing to the number of cells generated during embryogenesis is how the stem cell divides. This can either be by symmetric divisions where the stem cell generates two daughter cells with the same fates, or by asymmetric divisions where the stem cell self-renew and generates a daughter cell that has lost stem cell properties (Gotz and Huttner 2005). The symmetric divisions are proliferative and can expand the number of stem cells and have the potential to generate a large number of cells, while the asymmetric divisions maintain the number of stem cells but also generate daughter cells that can differentiate into neurons and glia. In addition, the daughters generated by the stem cell can either differentiate directly or divide one or several times before these daughters differentiate. These different modes of division greatly influences the number of cells generated from a single stem cell. 
How is the generation of this diversity of cell types accomplished? Early in development, neural stem cells are competent to generate all the cells in the CNS, and in the embryo there is a massive proliferation of cells (Muotri and Gage 2006; Franco and Muller 2013). The CNS is divided into different areas by expression of region-specific genes, and this will instruct the neural stem cells which cell types to produce (Guillemot 2007; Paridaen and Huttner 2014). Each neural stem cell produces a lineage of daughters in a predetermined birth order with respect to the identity they will acquire (Franco and Muller 2013). The daughters have minimal ability to self-renew, and instead activate differentiation programs. This means that the neural stem cells generate different cells at defined times and positions (Guillemot 2007).

\section{Developmental progression}

Embryonic development requires shifting gene expression to generate different tissues and within them different cell types. Developmental progression in gene expression and determination of cell fates demands coordination in the sequential gene expression, so that a cell takes on a path and stays on it. Neural stem cells becomes restricted in competence in a stepwise manner, where they are first competent to generate all the cells in their lineage but gradually lose this competence and cannot produce cells earlier in their lineage (Desai and McConnell 2000; Isshiki, Pearson et al. 2001; Li, Chen et al. 2013). Information, both intrinsic and extrinsic, is processed to change gene expression over time. Gene expression is initiated or repressed depending on transcription factors (TFs), co-factors, interactions between TFs and cofactors, and the chromatin landscape that can permit binding of TFs or be in a closed state where TFs cannot bind (Davidson 2010; Spitz and Furlong 2012). Binding of TFs to regulatory elements can also prime genes so they can be rapidly activated upon change in state. Many developmental genes are also regulated by several regulatory regions, and they can be used at different time-points during development to control different spatiotemporal expression. To ensure that the developmental path is followed, by transitions from one state to the next in a unidirectional manner, progression of development often activates a set of genes that at the same time both activate one state and repress the others (Spitz and Furlong 2012). Feed-forward regulation of gene expression can ensure that once a path has been entered, it is followed. Feed-forward activation of the sequential genes assures that the path is followed, and inhibition of alternative paths assures that there are no other alternatives to take. Inhibiting gene expression can be done by remodeling the chromatin to make it inaccessible for transcription factors, but it can also be actively repressed (Spitz and Furlong 2012). Developmental progression is regulated by gene regulatory networks, where several genes, needed for the transitions, are activated at the same time (Davidson 2010). For cell fate choices, genes that encode TFs that antagonize the expression of each other and further activate their own expression are often first co-expressed, but a slight shift in the balance of expression is amplified and induces fate choices in both cells (Davidson 2010). This ensures that once a choice is made, this fate is maintained both by active transcription of the genes necessary to maintain it, but also by repressing alternative states. For terminal differentiation, it is necessary to inhibit transition back to a more pluripotent state (Davidson 2010). 


\section{Diseases associated with defective brain development}

The human brain is responsible for cognitive functions, and therefore dysfunctional brain development can generate psychiatric disorders, such as depression and schizophrenia. A decrease in adult neurogenesis, with a decrease in proliferation, can generate cognitive impairments and has been observed in many psychiatric disorders (Kang, Wen et al. 2016). Also, stress has been linked to reduced neurogenesis, and this has been suggested to increase the risk of depression (Schoenfeld and Cameron 2015). In addition, a reduction in size of some brain areas has been observed in patients with mental disorders.

The coordinated generation of different cell types at specific time-points indicates that this is strictly regulated, but what happens if this regulation is defective? Reduced proliferation during CNS development can result in an under-developed brain (microcephaly), loss of the cortical folds (lissencephaly) or cognitive impairments. On the other hand; losing control of proliferation can generate an excess of cells i.e., macrocephaly, or develop into cancer. Cells that have gained self-renewal capacity can grow in an uncontrolled manner, bypassing the normal control mechanisms. Many genes that normally function to promote self-renewal in progenitors are oncogenes and many genes that inhibit self-renewal are tumor suppressor genes (Shackleton 2010). The lost regulation of stem cell function has an important role in the origin of cancers. Identification of mechanisms that control proliferation is therefore important for identifying targets for therapeutics.

\section{The Drosophila CNS}

For my studies I have used Drosophila melanogaster as a model system. The first use of Drosophila was initiated over a century ago by Morgan (Morgan 1910), who received the Nobel Prize in 1933 for his studies of genetics using Drosophila as a model organism. There are many reasons for why this is a good model system, including that Drosophila has a short generation time, produces large numbers of offspring and is easily manipulated genetically (Hales, Korey et al. 2015). From fertilization to an adult fly it only takes around 10 days at optimum temperature, and embryonic development is completed within $24 \mathrm{hr}$. There are many genetic tools available, such as the GAL4/UAS transgenic misexpression system. This system can be used to express a DNA sequence in a desirable way, where the GAL4 determines the expression pattern and the UAS determines what shall be expressed. Another way to manipulate gene expression is through generation of transgenic flies, which carry DNA of interest and possibly express fluorescence genes.

As stated above the CNS is a complex organ composed of many different cell types, and for studying the development of the CNS Drosophila is a good model system. Although the mammalian CNS is much larger than that of Drosophila, many aspects of neurogenesis are conserved from Drosophila to mammals, showing a functional conservation between different species in the developing brain (Homem and Knoblich 2012). Using Drosophila as a model system enables studies of early neurogenesis in a less complex setting than that of vertebrates, but with many of the same fundamental regulatory programs. The genome of Drosophila has 
been sequenced, and analysis of homology to humans has shown that many of the genes associated with diseases in humans have orthologs in Drosophila, including genes associated with cancer (Adams, Celniker et al. 2000; Rubin, Yandell et al. 2000; Hales, Korey et al. 2015). The CNS of Drosophila can be subdivided into the brain and the ventral nerve cord (VNC), and the VNC can be further subdivided into three thoracic (T1-T3) and ten abdominal (A1-A10) segments (fig 1). The initial step in development of the nervous system is defining which cells that will constitute the future nervous system. Following gastrulation, the nervous system arises from the neuroectoderm, and the neuroblasts (NBs), the neural stem cells in Drosophila, are born via a process of lateral inhibition, where a subset of neuroectodermal cells are selected for becoming NBs (Skeath and Thor 2003; Hartenstein and Wodarz 2013). The neuroectoderm is patterned both along the anterior-posterior (AP) and dorsal-ventral (DV) axes (Skeath and Thor 2003). Along the AP axis, the patterning starts with mRNAs contributed by the female to the egg. These will activate expression of gap genes, which in turn activate expression of pair-rule genes that lastly activate expression of segment-polarity genes, expressed in stripes. Along the DV axis, expression of the columnar genes is induced by gradients of morphogens. The AP and DV patterning genes in combination divide the neuroectodermal cells, creating an Cartesian coordinate system of unique combinations of expressed columnar and segment-polarity genes. This coordinate system is also used to name the NBs, where the name tells from which row and column they are born. Examples are NB56 , born in row 5 and column 6 , and NB3-3, born in row 3 and column 3, that have been used in this thesis to study lineage progression. Upon NB delamination, each NB has a unique identity and different NBs will express different identity genes. In addition, the Hox genes act to confer differences between segments (Prokop, Bray et al. 1998). The equivalent NB in different segments can differ in the lineages it creates, such as when it terminates proliferation, as well as which and how many cells that go through programmed cell death. Overall this results in a smaller number of cells born and surviving in the abdominal segments than the thoracic, in the end producing a CNS that is larger in the anterior part.

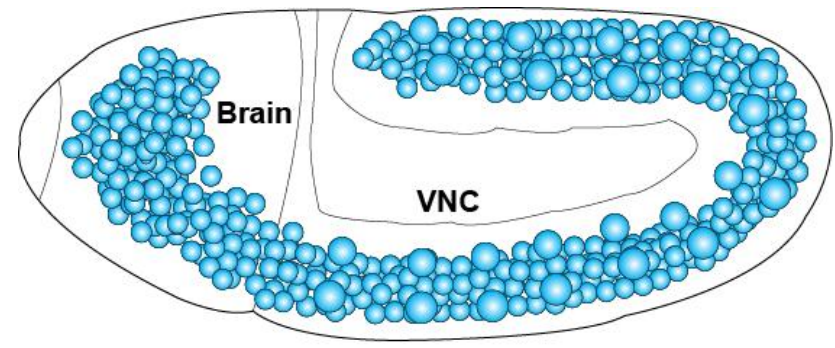

NB

Fig 1. Schematic picture of a Drosophila embryo at early development, when the NBs have been born. The CNS can be subdivided into the brain and the VNC. Adapted from (Baumgardt, Karlsson et al. 2014).

Every unique NB will produce a stereotyped lineage that is typical in size, but different NBs differ in how many daughters they produce ranging from 2-40 cells (Maurange, Cheng et al. 2008). At the end of embryogenesis, these NBs will have produced all the cells that constitute 
the nervous system, which for the VNC is $\sim 10,000$ cells (Schmid, Chiba et al. 1999; MiguelAliaga, Allan et al. 2004). Many NBs generate both neurons and glia, while some exclusively generate neurons (Schmid, Chiba et al. 1999; Skeath and Thor 2003). The NBs also go through temporal transitions in gene expression, and these different temporal factors are inherited by the daughters and contributes to neuronal specification ( $\mathrm{Li}$, Chen et al. 2013). Specifying the identities of neurons and glia are thereby initiated already before delamination, temporal differences in gene expression shifts competence, and the genetic profiles of cells in the CNS are predetermined. 


\section{Neuroblast delamination}

The VNC arises from the two ventral neurogenic regions of the ectoderm. Early in development, AP and DV patterning genes establish neurogenic regions of the ectoderm, and further pattern these areas, creating a Cartesian coordinate system of expression of genes (Skeath and Thor 2003; Technau, Berger et al. 2006). This generates equivalence groups of cells within the neurogenic regions that have the ability to adopt NB fate, but also each equivalence group is unique in its positional identity. One NB will arise from each equivalence group while the other cells adopt epidermal fate (Doe 1992). Because of this unique expression profile and the stereotyped time point and position of formation, each NB can be identified.

\section{The proneural genes}

NBs delaminate in five sequential waves, and after the last wave $\sim 30$ unique NBs in each hemisegment are generated (Broadus, Skeath et al. 1995; Hartenstein and Wodarz 2013). Delamination is coordinated by two processes: expression of proneural genes of the achaetescute complex $(A S-C)$ that make the cells in the equivalence group competent to generate a $\mathrm{NB}$, and lateral inhibition to restrict the competence to only one cell in each equivalence group (Hartenstein and Wodarz 2013). The cell that expresses $A S-C$ genes at a higher level than the neighbors is singled out, enlarges and delaminates (fig 2). The $A S$ - $C$ genes use the positional information to specify the identity of the NB (Bertrand, Castro et al. 2002); patterning genes restrict the expression of proneural genes (Martin-Bermudo, Martinez et al. 1991; Skeath and Carroll 1992). The proneural genes of the $A S-C$ include achaete (ac), scute $(s c)$ and lethal of scute (l'sc), and they are all required and sufficient to promote generation of NBs (Bertrand, Castro et al. 2002). The defining features of the proneural genes are their expression in the ectoderm, that they are both required and sufficient to promote generation of NBs, and that they are bHLH transcription factors. The AS-C are mainly activators of expression (Cabrera and Alonso 1991). Embryos mutant for the $A S-C$ present fewer NBs, and those that delaminate produce fewer daughters and die earlier (Jimenez and Campos-Ortega 1990). The opposite is seen when $A S-C$ is over-expressed; more NBs delaminate. AS-C proteins form heterodimers with Daughterless (Da), and this complex is then able to bind DNA (Cabrera and Alonso 1991; Bertrand, Castro et al. 2002). Although NBs can delaminate without $d a$, it is needed after delamination for NBs to divide and express NB genes, and double mutants for $A S-C$ and $d a$ have a more severe phenotype than $A S-C$ alone (Jimenez and Campos-Ortega 1990; Vaessin, Brand et al. 1994). 


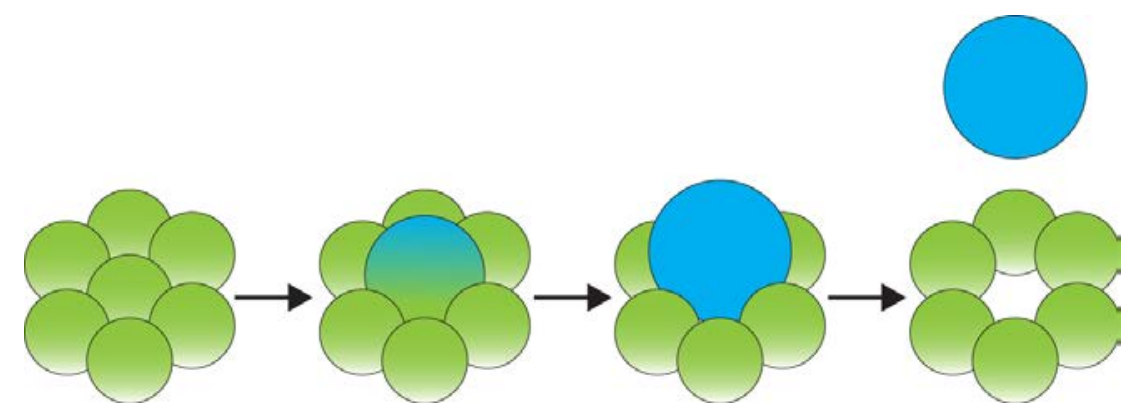

Fig 2. NB delamination. From the neuroectoderm, one cell acquires higher expression of $A S-C$ than the surrounding cells, down-regulate Notch signaling, start to enlarge and finally delaminate.

\section{Lateral inhibition}

Lateral inhibition is mediated by Notch signaling, where Notch signaling will be downregulated in the NB and up-regulated in the surrounding cells (Hartenstein and Wodarz 2013). In the NB, AS-C proteins activate transcription of the Notch ligand Delta $(D l)$, which activates the Notch receptor on neighboring cells. This transcriptional activation is important, shown by mutation of the binding sites for AS-C in $D l$, which generates supernumerary NBs from an equivalence group (Kunisch, Haenlin et al. 1994). Besides activating expression of $\mathrm{Dl}$, AS-C also regulates the expression of the Notch signaling pathway target genes $E(\mathrm{spl})$ - $C$ (Kramatschek and Campos-Ortega 1994), and auto-regulates and enhances its own expression (Martin-Bermudo, Martinez et al. 1991; Culi and Modolell 1998). The opposite is true for the epidermal cells, where Dl ligand from the NB activates Notch signaling. Notch signaling induces expression of $E(\mathrm{spl})-C$ that suppresses neural development by repression of $A S-C$ and the targets of AS-C (Lecourtois and Schweisguth 1995; Heitzler, Bourouis et al. 1996; Nakao and Campos-Ortega 1996; Giagtzoglou, Alifragis et al. 2003). In this way there is feedback between Notch signaling and AS-C, that results in amplification of initially small differences in $A S-C$ expression and Notch signaling. NBs up-regulate expression of $A S-C$ and repress Notch signaling, while epidermal cells activate Notch signaling and thereby expression of $E(s p l)-C$ and repress expression of $A S-C$ (Martin-Bermudo, Martinez et al. 1991; Heitzler, Bourouis et al. 1996; Culi and Modolell 1998; Jacobsen, Brennan et al. 1998). This assures that only one cell will acquire NB fate and restrict the expression of $A S-C$ genes to only the NB (Doe 2008; Hartenstein and Wodarz 2013; Kang and Reichert 2015). The accuracy in choosing one cell is high, with errors occurring in less than $1 \%$ of cases (Hartenstein and Wodarz 2013).

To assure that only one cell in each equivalence group is chosen to become a NB, cis interactions between Notch receptor and ligand are also thought to contribute. This is achieved through shortening of the delay in the inhibitory signaling by interactions between receptor and ligand in the same cell. As a cell in the equivalence group expresses ligands, they first bind to the receptors in the same cell, and this interaction is inhibitory since it does not produce a signal (Hartenstein and Wodarz 2013). One cell, the presumptive NB, starts to produce more ligands than receptors and these ligands will interact with the surrounding cells 
(Jacobsen, Brennan et al. 1998). This was evident from over-expression of ligands, which can inhibit Notch signaling (Jacobsen, Brennan et al. 1998; Li and Baker 2004). At the same time, this cell cannot respond to ligands from surrounding cells since all receptors are bound in cis to the receptors in the same cell. These cis interactions ensure that the signaling is directional (Miller, Lyons et al. 2009).

\section{Asense}

Upon delamination, expression of the proneural genes are down-regulated while expression of other, NB-specific, genes are up-regulated (Hartenstein and Wodarz 2013). One of these is asense (ase), whose expression follows $A S-C$ down-regulation (Brand, Jarman et al. 1993). ase also contains a bHLH motif (Gonzalez, Romani et al. 1989), and belongs to the proneural genes (Bertrand, Castro et al. 2002). It is activated during neurogenesis and expression is first visible in NBs in the process of delaminating (Gonzalez, Romani et al. 1989; Brand, Jarman et al. 1993). Expression of ase is activated by the proneural genes (Brand, Jarman et al. 1993).

Ase binds to genes that are involved in nervous system development and cell fate determination (Southall and Brand 2009). This study, using DamID to identify Ase targets, also identified Notch pathway genes, differentiation genes and the cell cycle genes $C y c E$ and dap. The conclusion was that Ase may activate expression of NB genes and repress differentiation genes in NBs, while promoting differentiation in GMCs. However, the function of ase has not been addressed during embryogenic neurogenesis.

\section{Vertebrate proneural genes}

Vertebrate proneural genes are, similar to Drosophila, expressed in the developing nervous system (Bertrand, Castro et al. 2002). This family is more diverse in vertebrates, and expression is not limited to early development, rather expression has been detected throughout nervous system development (Guillemot 1999; Bertrand, Castro et al. 2002). Addition of subfamilies and expression patterns ranging from early to late development means that they are involved in several different aspects of neurogenesis (Lee 1997; Guillemot 1999). Although the functions are more diverse, some families of vertebrate proneural genes have a similar function to that in Drosophila and are involved in lateral inhibition. Mutations in these genes result in defects in neurogenesis, with fewer progenitors and defective Notch signaling (Guillemot 1999; Bertrand, Castro et al. 2002). 


\section{Asymmetric cell division}

During early embryonic development, cells often divide symmetrically, because these divisions expand the progenitor pool and generate large numbers of cells. Subsequently, progenitor cells switch to asymmetric cell divisions, renewing themselves while generating daughter cells with more limited potential. These decision are of critical importance because they control the number of cells generated in different tissues during development (Gotz and Huttner 2005). In Drosophila, NBs mostly divide by asymmetric divisions, renewing themselves while budding off daughter cells with a restricted proliferation potential. Asymmetric divisions require control of polarity, spindle orientation, proliferation and cell fate determination. This ensures that there is a balance between NBs that self-renew, and daughters that exit the cell cycle and differentiate.

The NB needs to be polarized for setting up the axis of polarity, directing spindle orientation, appropriate location of cell fate determinants and for spindle arms to be asymmetric in length (Homem and Knoblich 2012; Li 2013). The neuroectodermal cells are polarized, and when the NB delaminates it inherits this polarity (Hartenstein and Wodarz 2013). The axis of polarity is set up by complexes located at the apical and basal sides of the NB (fig 3). The Par complex and the Pins complex are located at the apical cortex, while cell fate and proliferation-restricting determinants are located at the basal cortex. It is the Par complex that is inherited from the neuroectoderm (Chang, Wang et al. 2012), and for maintenance of the apical location of the Par complex the NB needs to be in contact with the neuroectoderm $(\mathrm{Wu}$, Egger et al. 2008). The Par complex consists of Bazooka (Baz), Par-6 and atypical protein kinase C (aPKC), while Partner of inscuteable (Pins), G protein $\alpha$ i subunit (Gai) and Mushroom body defect (Mud) make up the Pins complex (Hartenstein and Wodarz 2013; Kang and Reichert 2015). These two complexes can compensate for each other, and are by themselves sufficient to mediate spindle asymmetry and generate daughters of different sizes (Cai, Yu et al. 2003). They do however have different functions under normal conditions (Izumi, Ohta et al. 2004). The Baz/Par-6/aPKC complex is responsible for maintaining the apical-basal polarity of the NB and for basal localization of cell fate determinants. The Gai/Pins/Mud complex is responsible for spindle orientation, by interaction between Mud and the centrosomes (Izumi, Ohta et al. 2006). The Pins complex, via Pins and Gai, is linked to Baz in the Par complex by Insc (Schaefer, Shevchenko et al. 2000), thereby linking apicalbasal polarity to spindle orientation.

At mitosis, a chain of phosphorylation events is initiated, which results in the localization of the cell fate determinants at the basal side of the NB. This is initiated by Aurora-A (AurA) phosphorylating Par-6, which releases the interaction between Par-6 and aPKC (Wirtz-Peitz, Nishimura et al. 2008). Since Par-6 has been inhibiting aPKC, aPKC can now phosphorylate Lethal giant larvae ( $\mathrm{Lgl})$ and release it from the apical cortex into the cytoplasm. This release of $\mathrm{Lgl}$ is essential to allow Baz to enter the complex, thereby exchanging Baz for Lgl. Numb can now be recruited to the complex, become phosphorylated by aPKC, and this phosphorylated Numb travels to the basal cortex. Numb is one of the cell fate determinants that localizes basally and is inherited by the GMC. Miranda (Mira) is also released from the 
apical cortex by phosphorylation by aPKC, placing Mira basally before mitosis (Atwood and Prehoda 2009). The other basal proteins are Brain tumor (Brat) and Prospero (Pros). These basal cell fate determinants inhibit self-renewal, promote cell cycle exit and activate genes promoting differentiation. Mira is an adaptor protein responsible for carrying Pros and Brat to the GMC (Lee, Wilkinson et al. 2006), but after division Mira is degraded and Pros and Brat are released and can enter the nucleus (Shen, Jan et al. 1997). Pros activates differentiation genes, repress genes promoting proliferation and regulates the expression of cell cycle genes (Choksi, Southall et al. 2006). Brat promotes cell cycle exit, repress NB fate and inhibits cell growth (Betschinger, Mechtler et al. 2006). Numb is assisted to correct localization during mitosis by Partner of Numb (Pon) (Lu, Rothenberg et al. 1998), and represses Notch signaling and specifies the asymmetric fates of siblings (Wang, Somers et al. 2006).

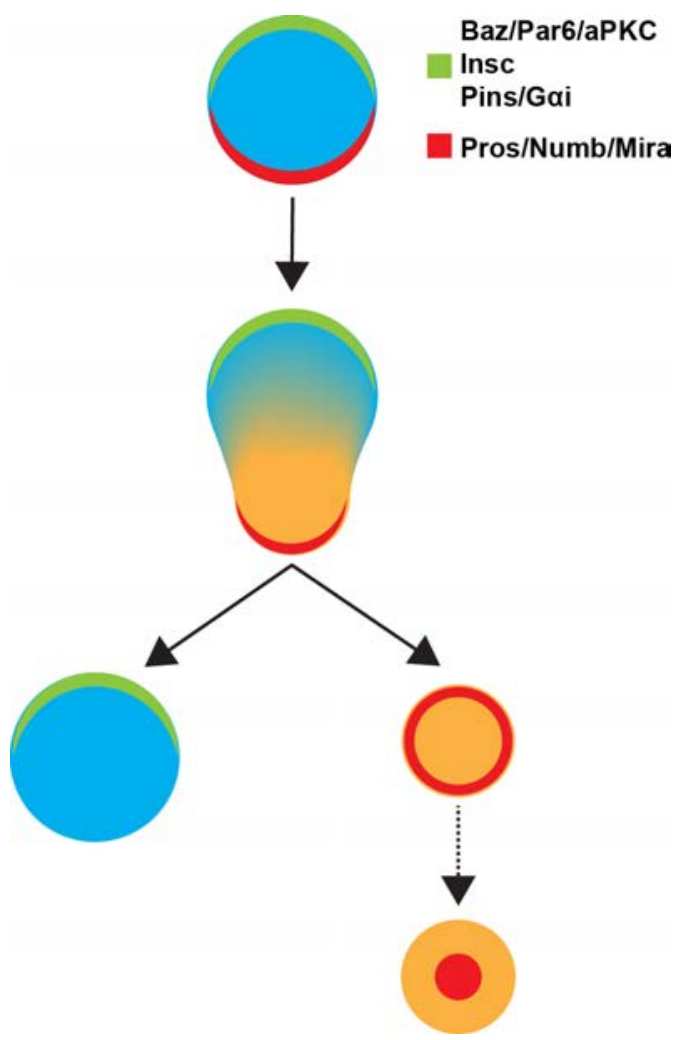

Fig 3. Asymmetric division. The apical and basal complexes set up the axis of polarity. At the apical side, the Par complex and the Pins complex are linked by Insc. At the basal side the cell fate determinants Pros/Numb/Mira are segregated to the GMC upon division.

\section{Asymmetric divisions and disease}

Asymmetric divisions maintain a balance between proliferation and self-renewal of NBs, and the generation of daughters which exit the cell cycle and differentiate. Perturbations of 
asymmetric divisions can lead to problems in cell fate determination, loss of polarity, incorrect spindle orientation, loss of proliferation control and ultimately tumor formation.

The spindle orientation is important for generating daughters of different sizes and with different fates. Disrupting the apical-basal orientation of the spindle can result in equal distribution of cell fate determinants into two daughters acquiring the same fate. One such case is aurA mutants, which have problems in localization of Numb and spindle alignment, ultimately leading to formation of brain tumors (Lee, Andersen et al. 2006). Shifting the division plane $90^{\circ}$ to orthogonal division generates two NB siblings (Cabernard and Doe 2009).

Segregation of cell fate determinants into daughter cells is important for generating a daughter that will differentiate. Mutants of brat are displaying overgrowth due to transformations of daughters into NBs (Betschinger, Mechtler et al. 2006). Mutants for pins, mira, pros or numb developed clones that grew many times larger than normal, could be transplanted into a new host, and damaged the surrounding organs through invasion (Caussinus and Gonzalez 2005). The tumors could be maintained, by serial transplantation into new adult host animals, for several years, proving to be immortal with unlimited proliferation potential. Some differences between the different genetic backgrounds were observed; that pins tumors had symmetric divisions while numb, mira and pros mutants had asymmetric divisions, but in the tumors the NBs divided in an uncontrolled manner. 


\section{Lineage control}

Within each VNC hemisegment, each $\mathrm{NB}$ is unique, and generates a lineage that is stereotyped in size and in the identity of neurons and glia generated. As the embryo develops the NB goes through rounds of asymmetric divisions where it renews itself and buds off daughter cells. How many rounds of divisions each NB goes through is highly variable, creating lineages that varies largely in cell number. Also, there are segmental differences for the same NB in lineage progression, where NBs generally terminate their lineage earlier in the abdomen (Maurange and Gould 2005). Because of this feature, a total of 500 cells are generated in each thoracic hemisegment and $\sim 400$ in each abdominal hemisegment, by end of neurogenesis (Skeath and Thor 2003).

\section{Division modes}

The mode in which NBs divide greatly influences the final number of cells produced. Generally, symmetric divisions, where stem cells divide to generate two cells with maintained proliferative capacity, can expand the pool of stem cells and have the potential to generate large number of cells (Fish, Dehay et al. 2008). In the VNC, NBs typically divide by asymmetric divisions, to renew themselves and generate a daughter cell with limited proliferative potential (Sousa-Nunes, Cheng et al. 2010). Initially, this daughter cell divides once to generate two neurons and/or glia (denoted type I). Subsequently, many NBs divide to renew itself while generating a daughter that directly differentiates into a neuron or glia (type 0 mode) (Baumgardt, Karlsson et al. 2009). During larval development, a third mode, type II, has been identified, where daughters divide multiple times. Hence, the types of divisions a NB can carry out, with different daughter behaviors, can be divided into three different division modes (fig 4). The mode of division has a great impact on the number of cells generated at the end of development given that the different modes have different proliferation potentials.

Type 0

Type 0 NBs divide asymmetrically to renew themselves and directly bud off a neuron or glia (fig 4A). This was initially showed in two different lineages in the VNC during embryonic development (Karcavich and Doe 2005; Baumgardt, Karlsson et al. 2009), and later to occur in other lineages as well (Baumgardt, Karlsson et al. 2014).

Type I

Type I NBs are found both in the VNC and the brain throughout development. The NB divides asymmetrically to renew itself and generate a ganglion mother cell (GMC) (fig 4B) (Doe 1992; Boone and Doe 2008). The GMC in turn divides once to generate two neurons and/or glia.

Type II

Type II NBs are found in the brain during postembryonic development. They divide to renew themselves while budding off an intermediate neural progenitor (INP) (fig 4C). These INPs are different from GMCs generated by type I NBs in that they can divide multiple times; the INP maintains mitotic capacity and divides to renew itself while budding off a GMC that in 
turn divide once to generate two neurons (Bello, Izergina et al. 2008; Boone and Doe 2008; Bowman, Rolland et al. 2008). The NBs differ from type I NBs by not expressing ase. Expression of ase is initiated during the maturation of the INP. Another difference from a type I NB is that although both the NB and INP divide asymmetrically, Prospero (Pros) is not distributed to the INP. Due to the proliferation potential of these lineages, disturbing them can generate a reverse of INPs back to NBs and tumor formation (Bowman, Rolland et al. 2008).
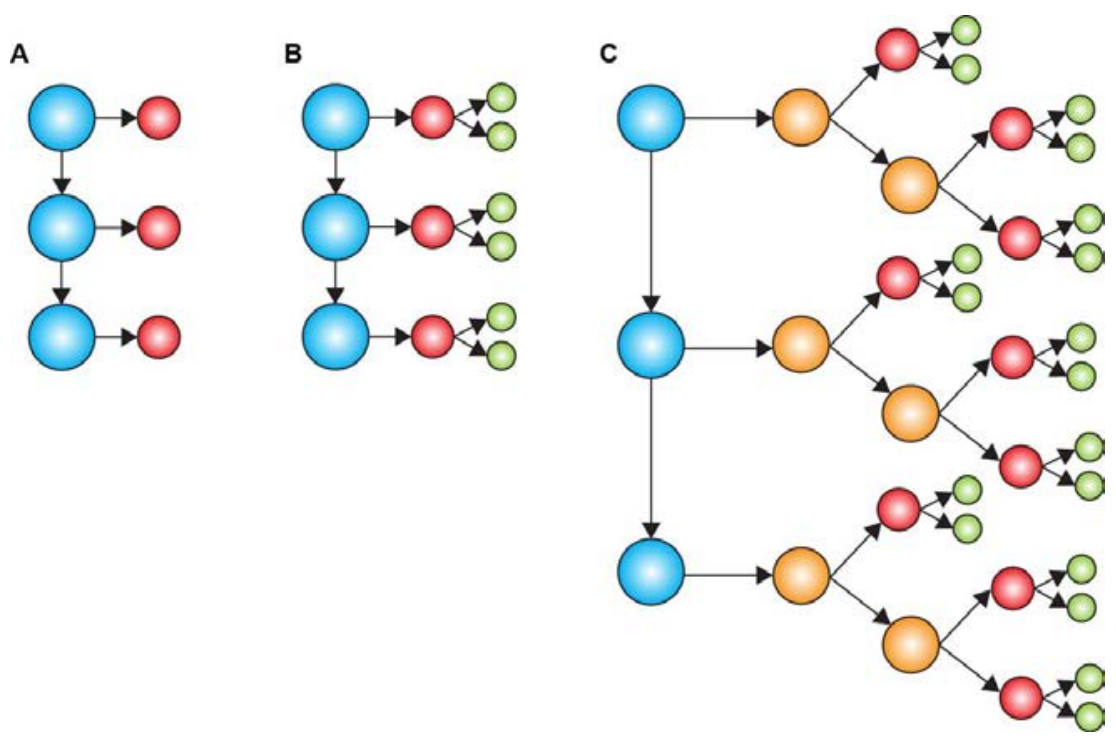

Fig 4. Division modes: (A) Type 0 where the NB divides to renew itself while generating a daughter that directly differentiates. (B) Type I where the NB divides to renew itself while generating a daughter that divides once to generate two neurons and/or glia. (C) Type II where the NB divides to renew itself while generating a daughter that in turn divides to renew itself while generating a daughter that divides once to generate two neurons and/or glia.

\section{The temporal cascade}

Most if not all embryonic NBs express a series of transcription factors in a sequential order, the temporal factors, which ensure that different types of neurons/glia are born at different time-points. These temporal factors are inherited by the GMC, which will maintain the temporal factors present at their birth, and the expression is briefly maintained in their daughters (Isshiki, Pearson et al. 2001). Since the GMCs will inherit different temporal factors, in addition to the positional information provided by the NB from the Cartesian coordinate system, each GMC and subsequently its two daughters (neurons/glia) has the potential to be given a unique identity (Skeath and Thor 2003; Kohwi and Doe 2013; Li, Chen et al. 2013).

During the embryonic development these temporal factors are, in order, hunchback $(h b)$, Krüppel $(\mathrm{Kr})$, nubbin (nub)/POU domain protein 2 ( $\mathrm{pdm} 2$ ) (referred to together as $p d m$ ), castor (cas) and grainy head (grh) (fig 5) (Brody and Odenwald 2000; Isshiki, Pearson et al. 
2001; Baumgardt, Karlsson et al. 2009). These factors are expressed sequentially, and one factor initiates expression of the next, while repressing expression of the previous and the next plus one. This ensures that activation of the next step is not activated prematurely and that the previous factor is downregulated (Isshiki, Pearson et al. 2001).

The sequence of transcription factors is independent of time of birth, meaning that irrespective of birth at first or last wave of delamination, NBs start expressing the temporal factors independently and then express the following genes in sequential order (Isshiki, Pearson et al. 2001; Kohwi and Doe 2013; Li, Chen et al. 2013). Not all NBs go through the complete cascade, and the lineage can be terminated at an early stage generating a small lineage (Karlsson, Baumgardt et al. 2010). The transitions in temporal factors are regulated intrinsically; isolated NBs cultured in vitro can progress through the temporal cascade (Brody and Odenwald 2000; Grosskortenhaus, Pearson et al. 2005). There are different mechanisms for timing temporal transitions in that the first transition is different from the following. For the NB to transition from $h b$ to $K r$ the NB needs to progress through the cell cycle and downregulate $h b$ expression. Arresting the cell cycle maintains $h b$ expression, preventing progression to $K r$ (Grosskortenhaus, Pearson et al. 2005). It has been shown in NB7-3 that $h b$ expression is activated before the first division and maintained in the first progeny (Novotny, Eiselt et al. 2002). After the first division, $h b$ expression is downregulated. If expression of $h b$ is maintained for a longer time the NB is kept in an early identity; the number of cells produced in the lineage is increased and they express markers indicative of early parts of the lineage (Novotny, Eiselt et al. 2002; Pearson and Doe 2003). If instead $h b$ expression is removed, the early part of the lineage is missing while the later part is produced (Novotny, Eiselt et al. 2002). Once $h b$ expression is downregulated, the NB becomes restricted in its potential to respond to ectopic expression and follows the consecutive transitions (Pearson and Doe 2003). Only $h b$ is able to maintain the NB in an early identity, ectopic expression of other factors in the temporal cascade can induce a prolonged window of expression and generation of cells that is normally generated when those temporal factors are expressed, but this is on behalf of the other identities (Cleary and Doe 2006). The following transitions do not require cell cycle progression, but follows by intrinsic regulation (Grosskortenhaus, Pearson et al. 2005). Each temporal factor specifies the neuronal fate of the cells generated during the window where it is expressed, and GMCs get restricted in their sensitivity to respond to ectopic expression of temporal factors when differentiating into post-mitotic neurons (Pearson and Doe 2003; Cleary and Doe 2006).

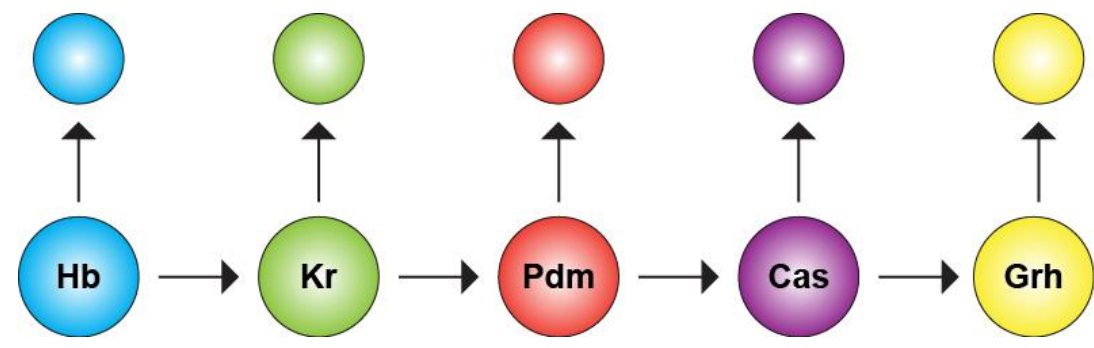

Fig 5. The temporal cascade. In sequential order, the NBs express $h b, K r, p d m$, cas and grh. 


\section{Switch in division mode}

Many, maybe all, NBs in the VNC switch in division mode from type I to type 0 at some point during lineage progression, a switch that is programmed to occur at a precise time (Baumgardt, Karlsson et al. 2014). The timing of the switch is different in different NBs, but is controlled by double mechanisms to ensure that the switch is executed at the correct time in that NB. First, the temporal cascade in combination with Hox genes control the timing of the switch. The temporal genes cas and grh, and the Hox gene Antennapedia (Antp) induce the switch by regulating expression of cell cycle genes (Baumgardt, Karlsson et al. 2014). Second, gradual activation of Notch signaling in the NB is needed for the switch to occur, where perturbations in Notch signaling results in a failure to switch (Ulvklo, Macdonald et al. 2012).

\section{Terminating lineage progression}

All NBs have to stop proliferate at the latest at the end of embryogenesis. The NB can choose to go into quiescence and be woken up again during larval stages, or to enter apoptosis. Some lineages stop earlier in development, but independent of when during development the lineage progression is terminated, the same choices remain. First, the NB can stop proliferating by going through apoptosis (fig 6C) (Novotny, Eiselt et al. 2002). Second, the NB can exit the cell cycle and after that go through apoptosis (fig 6B) (Karlsson, Baumgardt et al. 2010). Third, the NB can exit the cell cycle and enter quiescence, to be woken up again during larval stages (fig 6A) (Maurange, Cheng et al. 2008). There are segmental differences in the behavior of the same NB, in that many lineages are shorter in the abdomen than in thorax (Schmidt, Rickert et al. 1997; Prokop, Bray et al. 1998; Schmid, Chiba et al. 1999; Maurange and Gould 2005; Karlsson, Baumgardt et al. 2010). The decision which way to end the lineage at the end of embryogenesis is dictated by the combined action of the temporal cascade and Hox genes, as well as the segment-polarity and columnar genes (Tsuji, Hasegawa et al. 2008; Hartenstein and Wodarz 2013), thereby the time and place for exit from proliferation are coordinated.

A

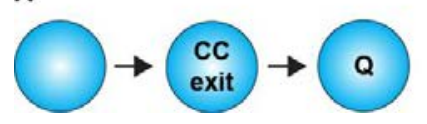

B

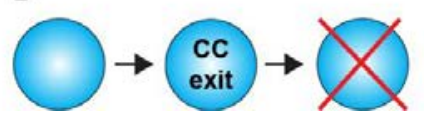

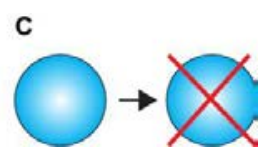

Fig 6. Termination of lineage progression. (A) The NB can exit the cell cycle (CC) and go into quiescence (Q). (B) The NB can exit the cell cycle and then go through apoptosis. (C) The NB can go through apoptosis without a previous cell cycle exit.

Apoptosis is mediated through a number of genes, and one key gene family in Drosophila is the RHG-family, which act to inhibit the inhibitor of apoptosis proteins (IAPs), thereby allowing caspases to execute programmed cell death (PCD) (Cashio, Lee et al. 2005). Several of the RHG-genes are located in one genomic region, and deletions of this region results in a complete loss of embryonic apoptosis (Tan, Yamada-Mabuchi et al. 2011). Hox genes can activate expression of the RHG genes, and this regulation of apoptosis by Hox genes is 
thought to be indirect (Maurange, Cheng et al. 2008). Hox genes initiate the schedule of elimination already at early development based on spatial position. This is based on observations of transplanted NBs that maintain their initial identity and generate a lineage according to their initial position (Prokop, Bray et al. 1998).

The events at the end of lineages has been studied in more detail in several studies (Maurange, Cheng et al. 2008; Rogulja-Ortmann, Renner et al. 2008; Tsuji, Hasegawa et al. 2008; Baumgardt, Karlsson et al. 2009; Karlsson, Baumgardt et al. 2010; Ulvklo, Macdonald et al. 2012; Baumgardt, Karlsson et al. 2014). In general, the combined action of temporal genes and Hox genes dictate when a NB will exit the cell cycle and go through apoptosis. Due to the spatial differences in Hox gene expression, the same NB in different segments can differ in their lineage size. NB5-6A stops within the $p d m$ window, and the Hox genes Ultrabithorax $(U b x)$, abdominal- $A(a b d-A)$ and Abdominal-B $(A b d-B)$ are necessary and sufficient for this termination (Karlsson, Baumgardt et al. 2010). NB3-3T enters quiescence, and quiescence is induced when switching from $p d m$ to cas (Tsuji, Hasegawa et al. 2008). Segmental differences are mediated by differential expression of the Hox genes Antp and $a b d-A$, where Antp induces quiescence while $a b d-A$ instead inhibits quiescence in NB3-3A. Another study identified that progression from cas to grh, in combination with expression of $A b d-A$, was necessary for the NB to enter apoptosis (Maurange, Cheng et al. 2008). One more example is NB7-3 in which Antp protects the NB from apoptosis in thorax, but Ubx induces apoptosis in the abdomen (Rogulja-Ortmann, Renner et al. 2008). Apoptosis was shown to be induced by activation of rpr. In addition to these studies in single NBs, NB proliferation in the whole VNC has also been investigated. Cell cycle exit was affected in mutants of both the temporal factors cas and grh, and in mutants of Antp (Baumgardt, Karlsson et al. 2014). It was also shown that apoptosis was affected, and that these factors regulate cell cycle exit by regulating the cell cycle genes (described in more detail in The cell cycle).

In addition to spatial differences in Hox gene expression, expression levels of pros also dictate the NB fate to instruct the NB to exit the cell cycle. Also here the temporal cascade instructs when to increase the levels of Pros, where switching from grh to the sub-temporal factor seven up ( $s v p$ ) removes inhibition of expression, resulting in increasing levels of Pros and NB cell cycle exit (Maurange, Cheng et al. 2008). Stopping the temporal cascade will prevent cell cycle exit, but loss of Pros also prevents entry into quiescence. In these NBs that exits the cell cycle and then enter quiescence, Pros is involved in two steps necessary for timely cell cycle exit (Lai and Doe 2014). First, low levels of Pros repress cell cycle genes and genes expressed by NBs to achieve exit from the cell cycle. Second, higher levels of Pros repress $d p n$, expressed by all NBs, which induce quiescence. The effect of loss of controlling lineage termination is survival of NBs into larval stages; NBs can maintain proliferative potential and generate excessive cells (Peterson, Carney et al. 2002; Bello, Hirth et al. 2003). 


\section{The cell cycle}

During the cell cycle the cell replicates its DNA and divides, a process that needs to be precisely controlled. The cell cycle needs to progress forward, without reversing back to the previous phase, to ensure proper division of the newly synthesized DNA between the daughter cells. Regulation of the cell cycle during development is of importance for determination of cell number, organ size and shape of tissues.

The cell cycle includes four phases: gap phase $1(\mathrm{G} 1)$, synthesis phase (S), gap phase 2 (G2) and mitosis (M) (Budirahardja and Gonczy 2009). After the first gap phase, G1, DNA replication occurs during S phase. This is followed by a second gap phase, G2, before mitosis in $\mathrm{M}$ phase. Withdrawal from the cell cycle upon terminal differentiation is done from G1, when cells can enter the quiescent state G0. In NBs the cell cycle is rapid and gap phases are short (Fichelson, Audibert et al. 2005).

\section{The cell cycle regulators}

For the progression of the cell cycle in Drosophila, as in other systems, complexes of cyclindependent kinases (Cdks) and cyclins play an instrumental role (fig 7). Cdks are present throughout the cell cycle, while cyclins are produced prior to the stage needed and degraded afterwards, resulting in oscillations in the levels of different cyclins during a cell cycle (Vodermaier 2004; Fichelson, Audibert et al. 2005; Budirahardja and Gonczy 2009). Specificity in different phases is accomplished by different complexes of Cdks and cyclins. Cyclin E (CycE)-Cdk2 is responsible for the G1-S transition, while Cdk1 associates with Cyclin A (CycA), Cyclin B (CycB), and Cyclin B3 (CycB3) to accomplish the G2-M transition (Knoblich and Lehner 1993; Jacobs, Knoblich et al. 1998; Fichelson, Audibert et al. 2005; Budirahardja and Gonczy 2009). In addition to being regulated by the binding to a cyclin, the Cdks are regulated by other means, to ensure kinase activation at the correct timepoint of the cell cycle. Cdk1, in addition to binding to CycA, can be phosphorylated to either activate or inhibit its activity. Activating phosphorylations are added by the CDK-activating kinase (CAK) complex (Larochelle, Pandur et al. 1998). Inhibitory phosphorylations are added by Wee1 and Myt1 (Campbell, Sprenger et al. 1995; Fichelson, Audibert et al. 2005), and these inhibitory phosphorylations can be removed by String (Stg; cdc25) (Campbell, Sprenger et al. 1995; Fichelson, Audibert et al. 2005). For Cdk2, phosphorylations have not been found to be required for regulating activity (Lane, Elend et al. 2000). Cdk kinase inhibitors (CKIs) can block the activity of Cdk-cyclin complexes. Different CKIs block different complexes, thereby acting in different phases of the cell cycle. Dacapo (Dap; p21CIP1, p27KIP1, p57KIP2) can block the activity of CycE-Cdk2, to thereby inhibit the G1/S transition and maintain the cell in the G1 phase (de Nooij, Letendre et al. 1996; Lane, Sauer et al. 1996). Roughex (Rux) can block the activity of cyclin-Cdk complexes responsible for the G2/M transition. This is achieved by reducing the kinase activity of CycACdk1, thereby preventing activating phosphorylation of Cdk1 (Foley, O'Farrell et al. 1999). 


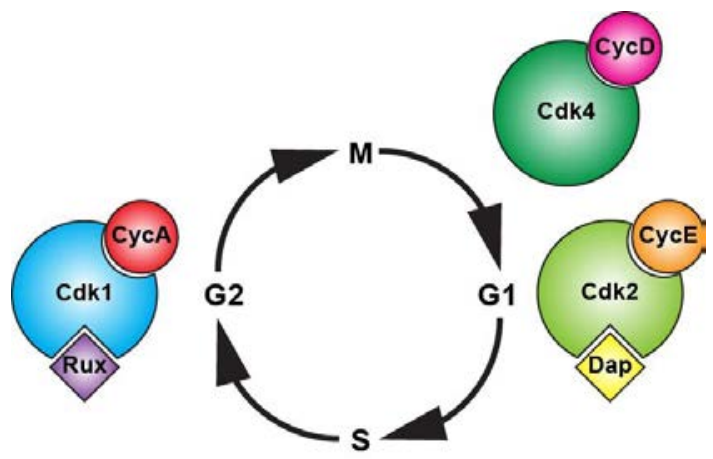

Fig 7. The cell cycle regulators. At G1, CycE-Cdk2 regulates the G1/S transition. CycD-Cdk4 stimulates cellular growth. At G2, CycA-Cdk1 regulates the G2/M transition.

The degradation of cyclins ensures that the activity of each Cdk-cyclin complex is timelimited and that the cell cycle continues forward without reversal to the previous step, by eliminating the factors needed for activation of the previous phase. The cyclins are destroyed by ubiquitin-mediated degradation, and different degradation complexes are responsible at the different phases of the cell cycle. CycE is degraded after S phase by the Skp1-Cullin-F-box (SCF) complexes, while the mitotic cyclins $\mathrm{CycA}, \mathrm{CycB}$ and $\mathrm{CycB} 3$ are degraded by the anaphase-promoting complex (APC) (Vodermaier 2004). The SCF complex recognizes CycE by a PEST sequence and the $\mathrm{APC}$ complex recognizes $\mathrm{CycA}, \mathrm{CycB}$ and $\mathrm{CycB} 3$ by a destruction box (Vermeulen, Van Bockstaele et al. 2003).

\section{Cell cycle progression}

In G1, the cell evaluates if it should commit to a new cell cycle (de Nooij, Letendre et al. 1996). Following the previous mitosis the cell must increase in size before entering another round of division. Divisions without increase in size will cause reduction in cell size and eventually apoptosis. This is regulated by Cyclin D (CycD)-Cdk4, which is not required for cell cycle progression in Drosophila, but stimulates cellular growth (Datar, Jacobs et al. 2000).

\section{G1/S transition}

The transcription factors of the E2F family play key roles during cell cycle progression. The E2f1 factor, which typically acts in complex with the DP factor, is executing the transition from $\mathrm{G} 1$ to $\mathrm{S}$ phase, by activating transcription of genes required for entry into $\mathrm{S}$ phase (Stevaux and Dyson 2002). In G1, Retinoblastoma-family protein (Rbf) inhibits E2f1 by binding and turning it into a repressor (Dyson 1998; Stevaux and Dyson 2002). In Drosophila there are two $E 2 f$ genes, $E 2 f 1$ and $E 2 f 2$, with antagonistic functions, and both proteins partner with DP and Rbf (Frolov, Huen et al. 2001). CycE-Cdk2 is the complex responsible for entry into and progression through $\mathrm{S}$ phase. CycE-Cdk2 phosphorylates Rbf and together with E2f activates its own expression, thereby promoting S phase entry (Knoblich, Sauer et al. 1994; 
Dyson 1998). The importance of CycE for the G1-S transition is seen in $C y c E$ mutants, which arrest in G1 (Duronio, Bonnette et al. 1998), and ectopic expression of $C y c E$ can push a cell to enter a new cell cycle (Knoblich, Sauer et al. 1994). CycD-Cdk4, although not required for cell cycle progression, aids in S phase entry by phosphorylating Rbf, releasing E2f1-DP from Rbf inhibition and allowing E2f1-DP to activate transcription (Dyson 1998; Datar, Jacobs et al. 2000). The role of E2f1 in initiating $\mathrm{S}$ phase is evident by ectopic expression of E2f1, pushing the cell into S phase (Duronio, Brook et al. 1996), and that levels of E2f1 need to be downregulated for the cell to exit S phase (Dyson 1998). E2f1-DP regulates replication, and mutants of E2fl slow down replication rate (Duronio, Bonnette et al. 1998).

\section{G2/M transition}

$\mathrm{CycA}, \mathrm{CycB}$ and $\mathrm{CycB} 3$ in complexes with $\mathrm{Cdk} 1$ act to promote the $\mathrm{G} 2 / \mathrm{M}$ transition (Knoblich and Lehner 1993; Jacobs, Knoblich et al. 1998). Although all three cyclins are involved in regulating the cell cycle, only CycA is essential; cell divisions can occur without either $\mathrm{CycB}$ or $\mathrm{CycB} 3$ although the entry into mitosis is delayed and mitotic spindle formation is disturbed (Knoblich and Lehner 1993; Jacobs, Knoblich et al. 1998). Mutating both $C y c A$ and $C y c B$ allows the cell to progress through $\mathrm{S}$ phase as DNA is replicated, but arrests the cell in G2 and blocks entering into mitosis (Knoblich and Lehner 1993).

Stg acts by dephosphorylating and activating Cdk1, which is important for the G2/M transition. Levels of Stg is limiting in the transition, and transcription of $s t g$ is activated at the end of G2 which promote the transition (Edgar and O'Farrell 1990). The importance of this transient expression of stg is evident in mutants which arrest in G2.

\section{M phase}

Removing the mitotic cyclins shows that there are some differences in their function during the $\mathrm{G} 2 / \mathrm{M}$ transition and progression through $\mathrm{M}$ phase. $C y c A$ mutants arrest in $\mathrm{G} 2$, thereby failing to enter $\mathrm{M}$ phase (Lehner and O'Farrell 1989). Both $C y c B$ and $C y c B 3$ mutants can divide but are delayed in mitosis, show spindle problems and sometimes difficulties in dividing properly (Jacobs, Knoblich et al. 1998). This suggests that the three cyclins have somewhat different and sequential roles in the regulation of the cell cycle with first CycA regulating entry into mitosis and the early part of $\mathrm{M}$ phase, and then $\mathrm{CycB}$ and $\mathrm{CycB} 3$ follows regulating the latter part of $M$ phase and exit from M phase (Knoblich and Lehner 1993; Budirahardja and Gonczy 2009).

\section{The cell cycle in a NB lineage}

The aforementioned description of the Drosophila cell cycle has mostly been addressed in the embryonic ectoderm and in the developing wing and eye discs. During development, the NB divides for a predetermined number of times, while generating daughters with a more restricted proliferation potential or without potential to divide. The cell cycle must therefore be controlled in the NB and in the daughters. The role of 21 cell cycle factors, including all of 
the abovementioned factors, were studied in detail in two NB lineages, as well as the entire ventral nerve cord. This revealed that the G1/S regulators CycE and E2f1, as well as Stg, were critical for NB and daughter proliferation (Baumgardt, Karlsson et al. 2014). A number of other cell cycle factors, described above, show little or no effects, presumably due to maternal loading. In addition, Dap was also shown to be important during two time-points: for the switch in daughter division mode from type I to type 0 , as well as for the NB to exit the cell cycle at the end of lineage progression. Expression of dap is activated prior to the type $\mathrm{I}>0$ switch, and without its onset of expression the daughters continue dividing in the type I mode and over-expression of dap is sufficient to induce a premature switch in division mode. For exit of the NB from the cell cycle, the levels of CycE and E2f1 also need to decrease, and over-expression of $\mathrm{CycE}$ and $\mathrm{E} 2 \mathrm{fl}$ can override both the type $\mathrm{I}>0$ daughter proliferation switch and NB exit (Baumgardt, Karlsson et al. 2014).

The daughters generated during early lineage progression, in the type I mode, divide only once, and this demands limitations in the cell cycle. Upon terminal differentiation the cell exits the cell cycle and to accomplish this, levels of repressors of the cell cycle are increased while levels of activators are decreased. The activity of the CycE-Cdk2 complex is inhibited by upregulation of dap (Lane, Sauer et al. 1996). If CycE levels are not reduced the cell will not arrest in G1, and instead continue through one more cell cycle (Knoblich, Sauer et al. 1994). If Dap levels are not increased, on the other hand, the cell cycle exit is delayed (de Nooij, Letendre et al. 1996). Daughters have higher expression of dap, limiting their proliferation potential (Baumgardt, Karlsson et al. 2014). In type I daughters, Prospero plays a key role in this process, acting as a transcriptional repressor of several of the cell cycle genes (Li and Vaessin 2000; Choksi, Southall et al. 2006). In the type 0 daughters, the expression of $C y c E$ and $E 2 f$ is low, and dap is on, inhibiting these daughters to enter the cell cycle (Baumgardt, Karlsson et al. 2014). 


\section{The Notch pathway}

The Notch signaling pathway is highly conserved throughout evolution, and involved in widespread decisions during development, including proliferation, cell fate specification, differentiation and cell death (Kopan 2012). The effects of Notch signaling are context dependent, and even though the core pathway is the same in most processes, the pathway is differently regulated, thereby generating different outcomes (Koch, Lehal et al. 2013). By using the pathway in this context-dependent manner, it can even be used in different ways at different time-points in the same tissue. The core pathway is relatively simple in design, and requires direct contact between the signal-sending and the signal-receiving cell (Kopan and Ilagan 2009). The Notch pathway is used both during embryonic and adult development, and repeatedly in multiple processes with activity specific to the context (Koch, Lehal et al. 2013).

Mutations in the Notch receptor results in developmental defects in all animals tested (Kopan 2012). The gene dosage of Notch is important, and even small variations in signaling can result in diseases, such as cancer (Louvi and Artavanis-Tsakonas 2012). The outcome of Notch signaling is context dependent, and in cancer Notch can act both as an oncogene and a tumor suppressor. In vertebrates, Notch signaling controls whether a cell shall remain as a progenitor or differentiate (Koch, Lehal et al. 2013). Notch often inhibits neuronal differentiation and maintains progenitors, but can also act in the opposite manner. But Notch also functions at more levels during CNS development, and has been implicated in controlling cell fate. Notch regulates quiescence and cell cycle exit of neural stem cells, where there is a requirement of Notch to maintain stem cells (Koch, Lehal et al. 2013).

In Notch mutant embryos in Drosophila, many of the cells in each equivalence groups develop into NBs (Koch, Lehal et al. 2013). And the opposite effect is observed when expressing Notch ectopically i.e., inhibition of early neurogenesis (Schweisguth 2004). Notch functions during development can be divided into three categories: Lateral inhibition; lineage decisions; and inductive signaling (Bray 2006). Lateral inhibition, as described above, singles out one NB from an equivalence group of neuroectodermal cells. Binary cell fates, described in more detail below, are created by asymmetric distribution of Notch regulators into one daughter after a GMC division. Inductive signaling uses Notch signaling in patterning processes (Bray 1998; Bray 2006). Inductive signaling occurs between two populations of cells to segregate the groups, establishing boundaries between the groups. Notch is activated at the boundary between two groups of cells and the cells one side signal to those on the other side. This signaling induces expression of target genes to specify different cell types between the groups. Inductive signaling does not occur during progression of a NB through development and will therefore not be further described.

\section{The signaling pathway}

The Notch receptor is a transmembrane protein present on the cell surface (Hori, Sen et al. 2013). When the receptor comes in contact and binds a ligand, also transmembrane proteins, on the adjacent cell the receptor is cleaved in two steps (Bray 2006). The first step is at site S2 
by Kuzbanian (Kuz) (ADAM metalloproteinase) (fig 8). This enables a second cleavage at site S3 by $\gamma$-secretase. Upon this cleavage the Notch intracellular domain (NICD) is released and translocates to the nucleus. The other part of the receptor, the Notch extracellular domain (NECD), is endocytosed back into the signal-sending cell together with the ligand (Fortini 2009). In the nucleus of the receiving cell, NICD forms a complex with the DNA-binding protein Suppressor of Hairless $(\mathrm{Su}(\mathrm{H}))$ and the Mastermind (Mam) co-factor, as well as other transcriptional co-activators (Bray 2006). The NICD-Mam-Su(H) complex acts as an activator complex, and activates transcription of target genes (Kopan and Ilagan 2009). One wellknown group of target genes of Notch signaling is the genes in the Enhancer of split complex (E(spl-C), which are transcriptional repressors (Jennings, Preiss et al. 1994).

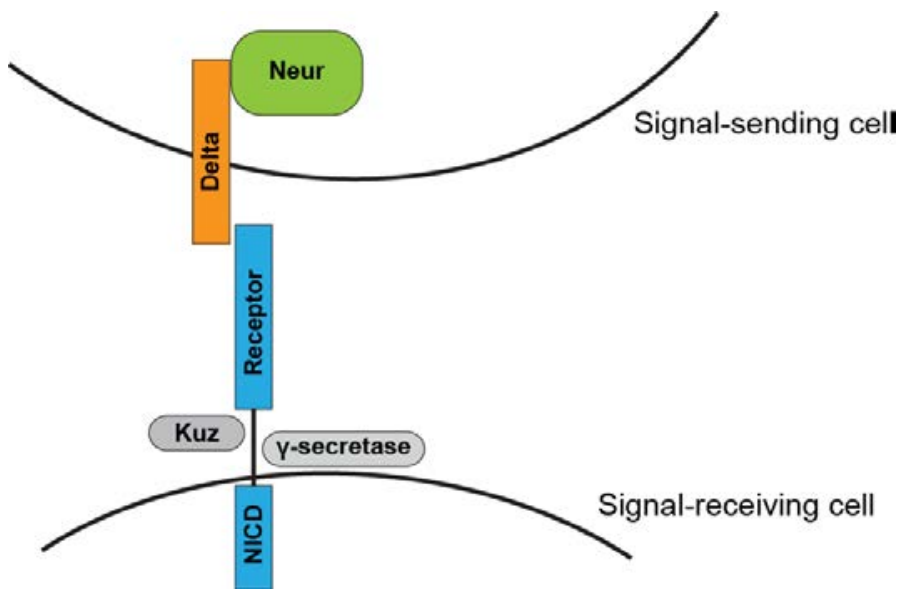

Fig 8. Activation of the Notch receptor. The Notch ligand Delta binds to the Notch receptor, and this induces cleavage of the receptor by Kuz and $\gamma$-secretase, releasing NICD.

\section{Regulation of signaling}

Activation of one Notch receptor generates one signal, and upon activation NICD translocates to the nucleus and activates transcription. Therefore regulating activation is an important step in determining the levels of signaling (Bray 2006). Besides regulating the transcription of receptor and ligand, the availability of receptor and ligand at the cell surface can be modified. Since every activated receptor only signals once, regulating the interaction of ligand with receptor is an effective way to regulate signaling (Kopan 2012). Both receptor and ligand are modified post-transcriptionally, which can result in signals that are different depending on context (see below) (Kopan and Ilagan 2009; Koch, Lehal et al. 2013).

\section{Ligands}

The Notch ligands in Drosophila are Delta (D1) and Serrate (Ser), which can substitute for each other functionally (Gu, Hukriede et al. 1995). In the signal-sending cell, the ligands can be ubiquitinated by the E3 ubiquitin ligases Neuralized (Neur), Mindbomb 1 (Mib1) and 
Mindbomb 2 (Mib2), resulting in their endocytosis and activation (Schweisguth 2004; Bardin and Schweisguth 2006; Kopan 2012). Neur and Mib have slightly different functions, where Neur seems to be the major E3 ubiquitin ligase used during neural development (Bardin and Schweisguth 2006). Also, the ligases have somewhat different affinities; Mib typically ubiquitinates Ser, while Neur typically ubiquitinates D1 (Chitnis 2006). Neur interacts with D1 to ubiquitinate D1, which is then accumulated in vesicles (Le Borgne and Schweisguth 2003). Ubiquitination and consequent endocytosis of ligands are important for effective signaling (Chitnis 2006), and one study showed that ligand endocytosis in the signal-sending cell is required for activation (Seugnet, Simpson et al. 1997). Other studies have shown that ligand endocytosis enhances the ability of the ligand to activate the receptor (Itoh, Kim et al. 2003), and inducing ligand endocytosis can activate Notch signaling (Bardin and Schweisguth 2006). Neur can be antagonized by members of the Bearded family (Bardin and Schweisguth 2006). The Bearded family inhibits endocytosis of ligands by inhibiting Neur to interact with the ligands, thereby blocking signaling.

\section{Receptor}

The availability of the Notch receptor at the cell surface, as well as modifications to the receptor to alter its response to ligands, can be regulated to modify signaling activity. Before it can be presented as an active receptor, the Notch receptor is cleaved at site S1 by Furin during trafficking through the Golgi complex (Hori, Sen et al. 2013). Different types of glucosylation of Notch are post-transcriptional modifications that can regulate Notch activity during its synthesis and secretion, and can alter the responsiveness to ligands (Hori, Sen et al. 2013). The Notch receptor can be endocytosed to regulate its availability for activation by ligands, and endocytosed Notch can either be recycled back to the cell surface or degraded (Bray 2006; Fortini 2009; Kopan 2012). If the receptor shall be sent for degradation, E3 ubiquitin ligases target it by ubiquitination.

\section{Activation of the receptor}

The Notch receptor is a transmembrane protein and for activation it needs to be cleaved at two sites. These cleavages are performed by Kuzbanian (Kuz) (ADAM-family metalloprotease) (Rooke 1996, Pan 1997) and by $\gamma$-secretase (Kopan and Ilagan 2009). The S2 cleavage site is protected from cleavage in the absence of ligands, but endocytosis of ligand and receptor into the signal-sending cell upon binding of ligand is thought to generate the force needed to separate the domains and expose the cleavage site S2 (Fortini 2009; Kopan and Ilagan 2009; Kopan 2012). The first cleavage releases the Notch extracellular domain, and remaining in the signal-receiving cell is the Notch extracellular truncation (NEXT) which is still anchored to the membrane (Ilagan and Kopan 2007). NEXT is a substrate for $\gamma$-secretase, which cleaves NEXT at S3 to release NICD (Ilagan and Kopan 2007; Kopan and Ilagan 2009). 


\section{The nuclear events: a transcriptional switch}

Activation of Notch signaling by cleavage of the receptor is irreversible, and since transduction of the signal requires release of NICD, each receptor can only signal once (Schweisguth 2004).

\section{The repressor complex}

Without NICD, $\mathrm{Su}(\mathrm{H})$ often associates with co-repressors and histone deacetylases (HDACs), and together with these repress target genes (fig 9) (Kopan and Ilagan 2009; Hori, Sen et al. 2013). For activation, these repressors need to be exchanged to open up the chromatin. $\mathrm{Su}(\mathrm{H})$ has a dual function mediating DNA binding at target genes by recruiting either co-repressors or co-activators (Kopan 2012). In mammals, several co-repressors have been identified and homologs for many exists in Drosophila, but their functions need to be determined (Bray 2006). In the peripheral nervous system (PNS), repression is mediated by Hairless $(\mathrm{H})$, recruiting co-repressors (Kopan and Ilagan 2009), but $\mathrm{H}$ has not been shown to function in development in the CNS (Hartenstein and Wodarz 2013).

\section{The activation complex}

Upon NICD translocation to the nucleus, it associates with co-activators to activate expression of target genes (fig 9). Without co-activators, NICD is unable to bind DNA and can therefore not activate expression (Fryer, Lamar et al. 2002). NICD first interacts with $\mathrm{Su}(\mathrm{H})$ (Fortini and Artavanis-Tsakonas 1994) and this can trigger release of co-repressors from $\mathrm{Su}(\mathrm{H})$ (Kopan and Ilagan 2009). The role of NICD in the activation complex is therefore often to release $\mathrm{Su}(\mathrm{H})$ from co-repressors and switching it to an activator of transcription (Bray and Furriols 2001). $\mathrm{Su}(\mathrm{H})$ directs NICD to target genes, but recognition of targets is independent of NICD (Kopan and Ilagan 2009). Su(H) binds only transiently to some of its targets, and NICD enhances the binding (Krejci and Bray 2007). This complex is recognized by Mam, that associates with the complex and can initiate transcription of the target genes (Kopan and Ilagan 2009). Mam recruits p300/CBP, a histone acetylase (HAT) (Krejci and Bray 2007), and promotes assembly of the initiation and elongation complexes (Fryer, Lamar et al. 2002; Bray 2006). Only when this complex is assembled is activation of transcription of target genes possible, and the components of the activation complex all have different and required functions; $\mathrm{Su}(\mathrm{H})$ for binding to $\mathrm{DNA}, \mathrm{NICD}$ to switch $\mathrm{Su}(\mathrm{H})$ into an activator of transcription, and Mam to initiate transcription (Fryer, Lamar et al. 2002). 


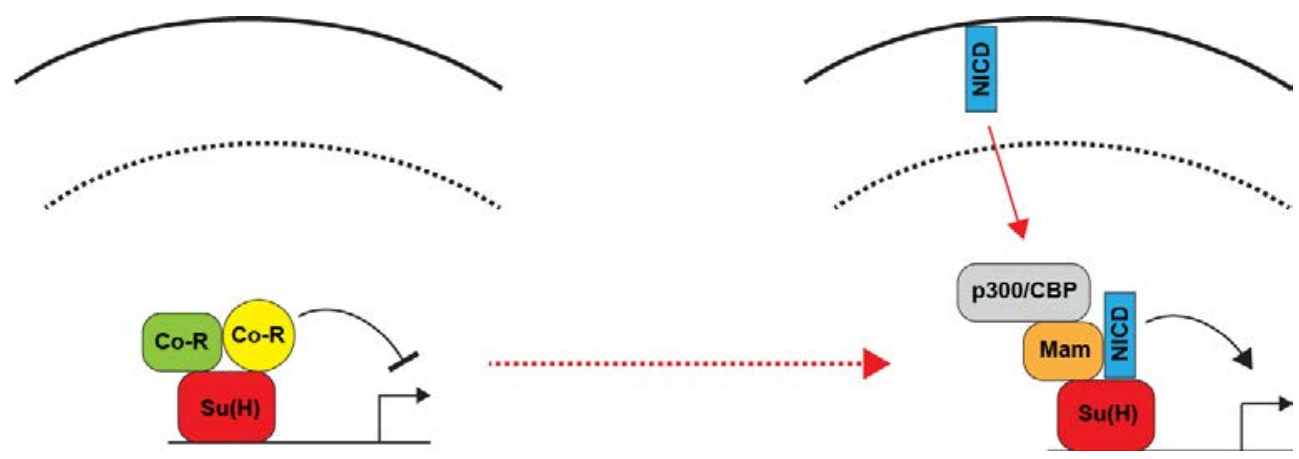

Fig 8. The transcriptional switch upon Notch activation. Without NICD, $\mathrm{Su}(\mathrm{H})$ associates with co-repressors and repress target genes. Upon Notch receptor activation, NICD enters the nucleus, associates with $\mathrm{Su}(\mathrm{H})$, recruits Mam and p300/CBP and activates transcription of target genes.

\section{The Enhancer of split complex}

The main targets of Notch signaling in the developing nervous system are the $E$ (spl-C genes, whose transcription is activated upon Notch signaling (Jennings, Preiss et al. 1994). The $E(s p l)-C$ encodes seven functionally redundant genes with a basic-helix-loop-helix-orange (bHLH-O) domain: $m \delta, m \gamma, m \beta, m 3, m 5, m 7$, and $m 8$ (Schrons, Knust et al. 1992). These are expressed in the nervous system, and in the PNS it is clear that different genes are expressed in different cells (Knust, Schrons et al. 1992). The specificity of expression in response to Notch signaling suggests that regulation involves additional factors to add specificity (de Celis, de Celis et al. 1996; Wech, Bray et al. 1999). Mutations in individual E(spl)-C genes shows no phenotypes due to functional redundancy (Delidakis, Preiss et al. 1991; Schrons, Knust et al. 1992; Ligoxygakis, Bray et al. 1999; Giagtzoglou, Alifragis et al. 2003), and therefore it has been difficult to study their individual roles (Wech, Bray et al. 1999). The E(spl)-C proteins are transcriptional repressors (Oellers, Dehio et al. 1994), and recruitment of Gro is required for function (Giagtzoglou, Alifragis et al. 2003). Gro is recruited to DNA by the $\mathrm{E}(\mathrm{spl})-\mathrm{C}$ proteins, and acts as a transcriptional co-repressor, that is needed during neurogenesis (Paroush, Finley et al. 1994).

\section{Down-regulation of the signal}

The Notch signal has a short duration and the half-life of NICD is limited, to quickly reset the cell for the next signal. For a response upon Notch signaling, only a transient activation is needed (Kopan 2012). After initiation of transcription, the complex is disassembled by degradation of NICD, which returns the cell competent to respond to the next signal (Kopan and Ilagan 2009). NICD is targeted for proteolysis by phosphorylation and ubiquitination (Lai 2002; Moberg, Mukherjee et al. 2004; Kopan and Ilagan 2009). In vitro studies suggest that Mam mediates recruitment of the factors that phosphorylates NICD (Fryer, White et al. 2004). 


\section{Binary cell fates}

When the GMC divides, the daughters can acquire different fates. For generation of daughters with different fates, the GMC divides asymmetrically and distributes cell fate determinants into one of the daughters (Bardin, Le Borgne et al. 2004). During these binary fate decisions Notch is instructive for one fate and inhibitory for the other (Skeath and Doe 1998; Cau and Blader 2009). Notch does not decide cell fate but is able to dictate different outcomes depending on context; other genes are involved in generating the different fates. Loss of Notch signaling and ectopic expression of Notch results in opposite phenotypes (Le Borgne and Schweisguth 2003). Numb is asymmetrically distributed to one of the siblings during GMC division, and blocks Notch signaling in the other sibling (Skeath and Doe 1998). This results in one sibling with Numb that blocks Notch signaling (B fate) and one sibling without Numb and active Notch signaling (A fate) (fig 10). Mutants with defective Notch signaling acquire two siblings with $\mathrm{B}$ fate, while numb mutants acquire two siblings with A fate. For the $\mathrm{aCC} / \mathrm{pCC}$ sibling pair, where the aCC with Numb becomes a motoneuron and the pCC with Notch signaling becomes an interneuron, it has been shown that Notch mutants transforms both cells into aCC neurons with gene expression according to this identity (Garces and Thor 2006).

A

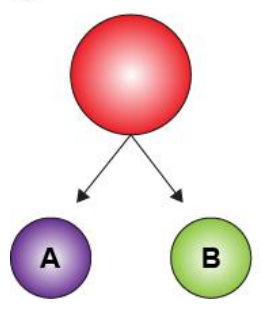

B

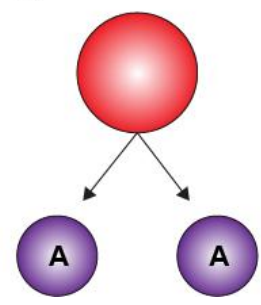

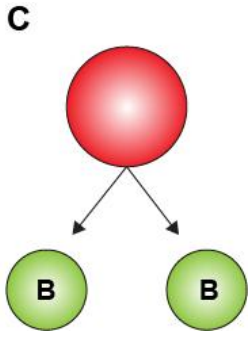

Fig 10. Binary cell fates. (A) Upon GMC division, Numb is distributed to one of the daughters (B fate), and the other daughter maintains Notch signaling (A fate). (B) numb mutants generates two daughters with A fate. (C) Notch pathway mutants generate two daughters with B fate.

Asymmetric segregation of Numb is in part mediated by Pon, which binds to Numb and assists in segregation during mitosis (Knoblich 2008). Numb is a membrane-associated adaptor that can bind to both $\alpha$-adaptin and Notch (Cayouette and Raff 2002), and thereby stimulates endocytosis, degradation, and down-regulation of Notch activity (Schweisguth 2004). $\alpha$-adaptin binds to Numb and this complex is asymmetrically segregated into one daughter, where Numb binds to Notch and $\alpha$-adaptin mediates endocytosis of NICD (Berdnik, Torok et al. 2002). Another mechanism for binary cell fate decisions is regulating the localization of Sanpodo (Spdo) (Fortini 2009). Spdo is localized to the cell surface where it is involved in activation of signaling (Nichols, Miyamoto et al. 2007). Numb can bind to Spdo and, together with $\alpha$-adaptin, mediate endocytosis of Spdo which removes Spdo from the cell surface. The asymmetric distribution of Numb therefore blocks Spdo from activating Notch in one of the siblings (Skeath and Doe 1998). In the sibling that does not inherit Numb, Spdo is found at the cell surface where it activates Notch signaling (O'Connor-Giles and Skeath 2003; Hutterer and Knoblich 2005). The other Notch pathway component that is also 
asymmetrically segregated during division is Neur, which can promote endocytosis and activation of signaling (Le Borgne and Schweisguth 2003). Loss of Neur generates cell fate transformations, but opposite to Numb it enhances Notch signaling.

Notch signaling also regulates apoptosis in a lineage-specific manner, where the binary cell fates decide which sibling that shall be eliminated (Karcavich 2005). In NB7-3, Notch signaling determines the fates of all the daughters generated (Lundell, Lee et al. 2003; Karcavich and Doe 2005).

\section{Notch controls the type $>\mathbf{0}$ daughter switch}

During progression of NB lineages, Notch is involved in three important processes: lateral inhibition, binary cell fate decisions, both described above, and switching daughter division mode, from type I to type 0 . As outlined above, NBs typically commence dividing in the type I mode, generating daughters that divide once, and subsequently switch to generating neurons that directly differentiate (type 0). Before the switch in division mode Notch is activated in the NB, and regulates the timing of the switch (Ulvklo, Macdonald et al. 2012). Changing Notch activity can result in a failure to switch; in Notch signaling mutants the NB continues to divide in type I division mode. 


\section{The Sox family}

The Sox family of genes are involved in different aspects of CNS development, and the number of members have expanded greatly from Drosophila to vertebrates (Kamachi and Kondoh 2013). This expansion is proposed to be due to gene duplication and divergence (Phochanukul and Russell 2010). In vertebrates this family contains at least 20 members, divided into eight subgroups (A-H) in vertebrates and five subgroups (B-F) in Drosophila based on sequence and function, where the group chiefly associated with CNS development is the SoxB subgroup (Phochanukul and Russell 2010; Kamachi and Kondoh 2013). Sox factors are transcriptional regulators containing a high-mobility group (HMG) domain that mediates binding to DNA, and upon binding bends the DNA (Ma, Niemitz et al. 1998; Kamachi and Kondoh 2013). The Sox proteins mainly function by associating with partners, and the partner dictates whether the Sox protein shall act as an activator or repressor. Expression of Sox genes is often auto-regulated, which is useful during development to stabilize an induced cell fate (Kamachi and Kondoh 2013). Often several members from the same Sox group are expressed in the same tissue, and share the same partner, which ensure proper development of that tissue. In Drosophila, the SoxB subgroup genes include SoxNeuro (SoxN), Dichaete $(D)$, Sox21a and Sox21b (Phochanukul and Russell 2010). Sox21a and Sox21b have not been studied in detail and will therefore not be discussed here.

\section{The SoxB group in Drosophila}

SoxN and D regulate genes with functions in CNS development, ranging from specifying a NB to terminal differentiation (Ferrero, Fischer et al. 2014). They are co-expressed in some areas and uniquely expressed in others, and can functionally compensate for each other (Overton, Meadows et al. 2002; Ferrero, Fischer et al. 2014). Due to this redundancy, mutating the single genes only generates mild effects, while mutating both results in severe defects in CNS development (Overton, Meadows et al. 2002). In double mutants, many NBs are not formed and the organization of the CNS is severely disrupted (Buescher, Hing et al. 2002; Overton, Meadows et al. 2002).

\section{SoxNeuro}

SoxN is expressed in the neuroetoderm throughout embryonic development and is essential for proper development of the CNS (Cremazy, Berta et al. 2000; Buescher, Hing et al. 2002). In SoxN mutants, NBs are lost in the lateral and intermediate columns (Buescher, Hing et al. 2002; Overton, Meadows et al. 2002). Expression of SoxN in NBs is low and transient, starting in neuroectoderm prior to delamination and is down-regulated when the NB has delaminated. In SoxN mutants, up-regulation of proneural genes prior to delamination does not occur, and expression of ase is reduced. Based on targets of regulation it has been proposed to have two main functions during development; early, to control genes specifying the NB, and late, to regulate differentiation and maturation of neurons (Ferrero, Fischer et al. 2014). This study used DamID and ChIP to find target genes regulated by SoxN, and SoxN was shown to regulate genes involved in asymmetric division, the temporal factors and the proneural genes. 


\section{Dichaete}

$D$ is widely expressed in the developing CNS, in the medial and intermediate columns (Zhao and Skeath 2002), and its function is required for CNS development. $D$ has several functions, including segmentation of the VNC and specification or maintenance of specific NBs in the brain (Nambu and Nambu 1996; Ma, Niemitz et al. 1998; Sanchez-Soriano and Russell 2000). $D$ is furthermore important for DV patterning of the neuroectoderm, and for NB formation (Zhao and Skeath 2002). The first indication for involvement in patterning was proposed to be through functioning in parallel to patterning genes, possibly by associating with them, to regulate gene expression during NB delamination (Zhao and Skeath 2002). A later study showed that $D$ can associate with patterning genes, and does so to repress the expression of $a c$ (Zhao, Boekhoff-Falk et al. 2007). Not only $a c$ is regulated by $D$, DamID and ChIP revealed binding of D across the AS-C and ase genes (Aleksic, Ferrero et al. 2013; Shen, Aleksic et al. 2013). D also binds to the temporal factors to activate their expression (Aleksic, Ferrero et al. 2013). The same study showed that D binds Pros, but D and Pros also share many target and may both collaborate to regulate these genes and antagonize each other. Expression of $D$ is down-regulated once the NB has delaminated (Zhao and Skeath 2002), and this downregulation is important for NB cell cycle exit and apoptosis during later development (Maurange, Cheng et al. 2008). Regulation of apoptosis is possibly regulated by direct transcriptional regulation since $\mathrm{D}$ binds the apoptotic genes, and cell cycle exit, by regulation of expression of $C y c E$ (Aleksic, Ferrero et al. 2013). Besides these functions in early development, $\mathrm{D}$ also regulates genes involved in terminal differentiation during later stages of development (Shen, Aleksic et al. 2013). Worth mentioning is the role $D$ has outside the embryonic CNS as a temporal factor in type II NBs (Bayraktar and Doe 2013) and in the optic lobes (Li, Erclik et al. 2013).

\section{Redundancy in the SoxB group}

Expression of SoxN and $D$ in the neuroectoderm overlaps in some areas, but there is also gene-specific expression, with SoxN expressed more laterally and $D$ more medially (Phochanukul and Russell 2010). Therefore, mutants for only one of the genes results in phenotypes in that area and compensation is not as effective. SoxN and D are both regulators of the genes necessary for NB formation and interact with the patterning genes (Phochanukul and Russell 2010). Both genes are needed for NB delamination, and bind to and regulate both patterning genes and the proneural genes (Nambu and Nambu 1996; Buescher, Hing et al. 2002; Zhao, Boekhoff-Falk et al. 2007; Aleksic, Ferrero et al. 2013; Shen, Aleksic et al. 2013; Ferrero, Fischer et al. 2014). The target genes for SoxN and D have been investigated in several studies, and from these it was evident that they share many target genes and therefore can compensate for each other (Ferrero, Fischer et al. 2014). Common features are that they are both required at different times during development and used differently in these contexts. Among the shared targets for SoxN and D are genes controlling self-renewal, asymmetric divisions and the temporal factors (Aleksic, Ferrero et al. 2013; Ferrero, Fischer et al. 2014). Later in development, they regulate genes involved in maturation and terminal differentiation (Ferrero, Fischer et al. 2014). DamID of SoxN and D in wild type and mutants showed that D and SoxN share many target genes, both those in early and those in late development (Ferrero, 
Fischer et al. 2014). But they did have some unique targets that the other group B Sox protein could not compensate for. The different types of responses were classified into five categories: compensation where the other factor could bind to the target, the loss of one factor did not result in binding of the other factor, loss of one factor resulted in increased binding of the other factor at the normal targets, mutants of one factor resulted in binding at de novo targets by the other factor, and loss of one factor removed binding by the other factor at the same target (Ferrero, Fischer et al. 2014). This indicates that they share many targets, but also have unique functions and in some cases are dependent on each other for binding. 


\section{The Snail family}

The Snail family of transcription factors have been found to have functions in diverse aspects of development ranging from cell fate determination, apoptosis to cancer (Hemavathy, Ashraf et al. 2000). snail was initially identified for its role in mesoderm formation, but has also been shown to be important in other processes during development (Nieto 2002). The Snail family encompasses a group of related zinc finger transcription factors, mainly acting as repressors at target genes (Ashraf and Ip 2001; Nieto 2002). The first gene discovered was snail (sna) in Drosophila, but the family now also includes worniu (wor), escargot (esg) and scratch (scrt) (Hemavathy, Ashraf et al. 2000). Based on the zinc finger regions, this family can be subdivided into the Snail and Scratch families (Hemavathy, Ashraf et al. 2000), where scrt mutants display no defects in nervous system development (Roark, Sturtevant et al. 1995), and will therefore not be further described. In vertebrates several homologues have been found, and an additional sub-family named Slug that is absent from Drosophila (Nieto 2002). Besides functions in mesoderm development, vertebrate Snail members have been shown to regulate progenitor proliferation and self-renewal by repressing apoptosis and regulating the cell cycle gene $C d c 25$ (Zander, Burns et al. 2014).

\section{The Snail family in the Drosophila CNS}

The first gene from the Snail family identified in Drosophila was sna, and expression of sna in the nervous system is first dynamic, but rapidly becomes restricted to NBs (Ip, Levine et al. 1994) (Alberga, Boulay et al. 1991). Expression of sna is not as high as for the other members in the VNC, where RNA in situ hybridization has shown that most NBs express wor and sna (Ashraf, Hu et al. 1999).

At first when analyzing mutants they did not appear to have a major function in CNS development, generating only mild phenotypes (Ashraf, Hu et al. 1999). This was found to be due to redundancy, where deletion of all three genes disrupts CNS formation. Expression of wor is restricted to the CNS and starts in delaminating NBs and is maintained after delamination. sna is also expressed in delaminating NBs, although at lower levels, while expression of esg is very low and transient (Ashraf, Hu et al. 1999; Ashraf and Ip 2001). Despite expression at delamination, at least the early waves of NB delamination are normal in mutants (Ashraf, Hu et al. 1999). On the other hand; deleting the proneural genes reduces the expression of wor and, to a lesser extent, sna (Ashraf and Ip 2001).

\section{The Snail family and asymmetry}

The first studies of wor observed defects in CNS development that correlate with GMC formation (Ashraf, $\mathrm{Hu}$ et al. 1999). In addition, removing all three Sna genes results in misplacement of the basal components and randomized spindle orientation, due to loss of Insc expression (Ashraf and Ip 2001; Cai, Chia et al. 2001). The Sna family regulates asymmetric divisions by regulating these genes, and in mutants Pros is not distributed to the GMC. This result in problems with asymmetric divisions, and one study showed that by also 
removing the asymmetric factor Pins, it was possible to generate symmetric NB divisions (Cai, Yu et al. 2003). Sna members regulate these genes involved in NB self-renewal at the transcriptional level (Southall and Brand 2009). Many of the target genes for Sna is shared with Ase, Dpn and Pros and include, besides NB self-renewal genes, also differentiation genes. Mutants of wor delays the cell cycle in NBs, and wor is needed to maintain selfrenewal and to inhibit premature differentiation (Lai, Miller et al. 2012). These mutants also maintain expression of the NB markers Dpn, Ase and Mira (Lai, Miller et al. 2012). The delay in cell cycle is possibly explained by regulation of $s t g$ expression, where expression of $s t g$ is reduced when removing all three genes (Ashraf and Ip 2001). Inhibition of differentiation can potentially be through suppression of elav expression, since wor mutants have increased levels of elav (Lai, Miller et al. 2012). 


\section{Aims}

The overall aim of this thesis has been to increase the knowledge on the genetic regulation of proliferation, especially the type $\mathrm{I}>0$ switch in division mode, to generate the correct number of cells of different identities. In more detail, the different projects aimed to:

\section{Paper I}

Elucidate if Notch signaling regulates the type I $>0$ switch globally, and how it regulates the switch. Furthermore, to investigate the downstream targets of Notch signaling, and the functions of individual $E(s p l)-C$ genes.

\section{Paper II}

Analyze the role of seq in lineage progression, both in NB5-6T and globally, to find out if it inhibits proliferation in more lineages than NB5-6T. Especially to investigate if it regulates the type $\mathrm{I}>0$ switch and how.

\section{Paper III}

Investigate how lineage progression, with different division modes, is regulated. In more detail, to see if there are early regulators which drive lineage progression. Furthermore to analyze their targets, to find out if they regulate the same targets as factors that stop proliferation, and if these also regulate each other. 


\section{Methods}

\section{Division mode in a lineage}

To study the division mode of single lineages, NB5-6T and NB3-3A have been followed over time and assayed for divisions of NBs and daughter cells. Embryos were dissected at different stages of development. The lineages were identified by transgenic markers; lbe $(K)$ - GFP for NB5-6T and eg-Gal4/UAS-GFP for NB3-3A. NBs were identified by expression of Deadpan (Dpn), and divisions by phosphorylated histone $\mathrm{H} 3$ (pH3). Dividing NBs could thereby be identified as the $\mathrm{Dpn}^{+}$and $\mathrm{pH}^{+}$cell within the lineage. Lineage divisions could be identified by $\mathrm{pH}^{+}$cells that are $\mathrm{Dpn}^{-}$.

\section{Global mitotic index}

For assaying proliferation in the VNC, dividing NBs and daughters has been quantified. NBs were identified by presence of Dpn, cortical localization of Pros and presence of $\mathrm{pH} 3$. Daughters were identified by nuclear localization of Pros, presence of $\mathrm{pH} 3$ and absence of Dpn. The number of dividing NBs and daughters were counted either manually or by a macro in ImageJ.

\section{Intensity measurements}

To investigate differences in expression levels of proteins between a control and mutants or over-expression genotypes, the levels of expressed protein was measured. Expression of the cell cycle genes and $E(s p l) m 8-G F P$ were measured in NBs, and NBs were identified as described above for global mitotic index. Mutant embryos or embryos over-expressing these factors were dissected on the same slide as control embryos. In this way, both the mutant/over-expression and the control were treated in the same way throughout the experiment. They were scanned with the same settings to enable comparison. For measurements of protein levels, either Photoshop or ImageJ were used. To compare separate experiments, the means were standardized to the mean value of control NBs and multiplied by volume or area to compensate for size differences. 


\section{Results and discussion}

\section{Paper I}

\section{Background}

Previous work had revealed that Notch signaling is involved in regulating the type $\mathrm{I}>0$ switch in NB5-6T (Ulvklo, Macdonald et al. 2012). Notch signaling is up-regulated prior to the switch, and perturbations to the pathway results in a failure to switch. But how does Notch signaling regulate the type I $>0$ switch, and does it regulate the switch globally? The main targets of Notch signaling are the genes of the $E(s p l)-C$ (Lecourtois and Schweisguth 1995), but are there additional genes regulated by Notch signaling to achieve the switch? Different $E(s p l)-C$ genes are expressed in different cells in the CNS (Knust, Schrons et al. 1992), but due to their functional redundancy it has not been possible to study their individual functions (Wech, Bray et al. 1999). Are there individual functions of the $E(s p l)-C$ genes, and which are the downstream targets of the $E(s p l)-C$ genes? A previous study showed that the cell cycle genes $C y c E, E 2 f$ and dap are important to orchestrate the timing of the switch, as well as the temporal factor cas and the Hox gene Antp (Baumgardt, Karlsson et al. 2014). Does Notch signaling and the $E(s p l)-C$ regulate or cooperate with any of these factors to regulate the timing of the switch?

\section{Findings}

Notch signaling regulates the switch in NB5-6T, but does this function apply to other lineages as well? We first turned to another lineage, NB3-3A, and could observe generation of extra cells in a $k u z$ mutant, as well as daughters proliferating ectopically. Perturbing Notch signaling in NB3-3A thus affects the type I $>0$ switch. We next turned to global mitotic index, and quantified the number of dividing NBs and GMCs globally in the VNC. As in NB5-6T and NB3-3A, we observed that the proliferation of daughters is increased in kuz mutants.

Notch signaling thus has an important role in the type I $>0$ switch globally, but how does it do this? The main targets of Notch signaling are the genes of the $E(s p l)-C$, and we first wanted to elucidate if individual genes have divergent functions in different lineages. By using TILLING mutants, CRISPR/Cas9 and recombineering, we generated single mutants of all of the $E(s p l)-C$ genes. To be able to study their individual functions in NB5-6T and NB3-3A, the single mutants were placed over a mutant removing all genes in the $E(\operatorname{spl})-C$, creating a sensitized background. By doing this, we found that some genes were acting in both lineages, but there were also individual differences. In $E(s p l) m 5, E(s p l) m \delta$ and $E(s p l) m \gamma$ mutants both NB5-6T and NB3-3A displayed extra cells, but $E(s p l) m 8$ and $E(s p l) m 3$ only affected NB3$3 \mathrm{~A}$, and $E(s p l) m 7$ only affected NB5-6T.

What are the targets of Notch signaling to regulate the switch? Since the cell cycle genes $C y c E, E 2 f$, stg and dap has previously been shown to be important for the switch (Baumgardt, 
Karlsson et al. 2014), we wanted to test if Notch signaling regulates the switch by interacting with these genes. In embryos heterozygous for $k u z$ and dap we could observe generation of more cells from NB5-6T. On the other hand, over-expressing dap could rescue the phenotype of the $k u z$ mutant. These effects were caused by changing the type I $>0$ switch, as only daughter divisions were affected. The switch is also regulated by cas and Antp (Baumgardt, Karlsson et al. 2014), so we asked if these genes act in a combinatorial manner with the $E(s p l)-C$ genes to orchestrate the switch. By over-expressing $E(s p l) m 8$ together with cas we could reduce proliferation of daughters and induce a premature switch. Since epistasis experiments showed that $k u z$ and the cell cycle genes interact, we tested if the $E(s p l)-C$ also regulates the cell cycle genes, and if this is done in concert with cas and Antp. To investigate the expression of cell cycle genes in different genetic backgrounds the levels of expression of the cell cycle genes were measured. This revealed that Notch signaling, when quantifying expression levels in $k u z$ mutants and $U A S-m 8$, up-regulates expression of dap. The $E(s p l)-C$ inhibits expression of $C y c E$ and $E 2 f$, and also up-regulates expression of dap. These results indicate that Notch signaling regulates the expression of the cell cycle genes. To investigate if this regulation is direct we turned to ChIP and DamID. Binding targets for $\mathrm{Su}(\mathrm{H})$ was analyzed by ChIP, for E(spl)m5 by DamID, and for E(spl)m8 by both ChIP and DamID. These results showed that $\mathrm{Su}(\mathrm{H}), \mathrm{E}(\mathrm{spl}) \mathrm{m} 5$ and $\mathrm{E}(\mathrm{spl}) \mathrm{m} 8$ bind to dap, CycE and stg, and as previously known $\mathrm{Su}(\mathrm{H})$ binds to the $E(s p l)-C$.

\section{Conclusions}

- Notch signaling regulates the type I $>0$ switch globally

- The $E(s p l)-C$ genes have individual functions

- Notch signaling regulates the type I $>0$ switch by regulating expression of the cell cycle genes

- Notch signaling works in two levels: at the first level NICD activates expression of the $E(s p l)-C$ and $d a p$, and at the second level the E(spl)-C repress expression of $C y c E, E 2 f$ and $s t g$ 


\section{Paper II}

\section{Background}

The sequoia (seq) gene was first identified and characterized in a genetic screen due to its effect upon dendritic branching in the larvae peripheral nervous system (Gao, Brenman et al. 1999; Brenman, Gao et al. 2001). It encodes a zinc finger transcription factor, with expression beginning early in development and localized to the nervous system. In addition to the problems in dendritic growth and branching in the mutant, Seq was proposed to function in the Notch signaling pathway, since the number of cells expressing Seq was dependent on Notch activity (Brenman, Gao et al. 2001). A connection to the Notch signaling pathway was further investigated in sensory organ precursors (SOPs) (Andrews, Giagtzoglou et al. 2009), concluding that Seq functions together with Notch in this context. Seq was proposed to act along Notch signaling in determining the cell fates, and to have a role in locking the specification of cell fates.

In the development of the retina, expression of Seq, acting in a temporal manner and at different levels, guides the axons to connect to the appropriate synaptic target layer (Petrovic and Hummel 2008; Kulkarni, Ertekin et al. 2016). In this context, Seq is required during a limited time for axons to connect properly, and different levels of Seq dictate both the spacing between axons and length of projections. By this dual function of Seq, greater differences in levels determine the length of projection and smaller differences determine spacing between the cells (Kulkarni, Ertekin et al. 2016). The responsiveness to Seq levels is time-limited and Seq acts in a temporal identity manner. In this context, Seq therefore has a different role from that shown in SOPs as involved in specifying the cell fates, instead acting to direct axon targeting.

The Seq protein has homology to the zinc finger DNA binding domains of Tramtrack (Ttk) (Brenman, Gao et al. 2001). In SOPs, Ttk has been proposed to have a similar role to Seq: integrating information and regulating expression of cell type specific genes. Perturbing the expression of $t t k$ in SOPs results in cell fate transformations (Guo, Bier et al. 1995), and $t t k$ is a downstream target of Notch signaling (Guo, Jan et al. 1996). In the CNS, Ttk maintains differentiation by blocking neuronal fate through repression of the neuronal genes asense (ase) and deadpan (dpn), and preventing progression of the cell cycle by inhibiting expression of $C y c E$ (Badenhorst 2001).

The zinc fingers of Seq also share some homology with the vertebrate PRDM family. These members can bind DNA directly, but more importantly they control gene expression by modifying the chromatin state at target promoters, by recruiting histone-modifying enzymes (histone methyltransferases (HMTs), HDACs and HATs) (Hohenauer and Moore 2012). In this way, they can promote a transition of a cell into a specific fate and repress the other possible fates, by changing the chromatin modifications at several targets. For example, they promote and maintain stem cell fate in embryonic stem cells (Hohenauer and Moore 2012). The selection of targets is under context-dependent control, which might in part be due to the binding partner. By acting as both activators and repressors, changing overall chromatin state, 
and acting in a context-dependent manner, PRDMs can perform the diversity of functions of specifying cell fate choice, drive cell differentiation and maintain specialized cell fates, as well as maintaining stem cell state (Hohenauer and Moore 2012). Several PRDMs are expressed in the CNS, in different areas and at different time-points (Kinameri, Inoue et al. 2008). It has been shown that PRDM14 is important for the maintenance of human embryonic stem cells, by regulating genes involved in self-renewal and differentiation (Chia, Chan et al. 2010).

\section{Findings}

The seq gene was identified in a screen in our lab for FMRFa expression, using FMRFa$e G F P$ as a reporter gene (Bivik, Bahrampour et al. 2015). Based on the extra FMRFa cells generated at the end of NB5-6T, and the known connection of Ttk and PRDMs to Notch signaling and cell cycle regulation, we wanted to elucidate the role of seq in lineage progression.

The role of seq during neurogenesis was first studied in two lineages: NB5-6T and NB3-3A. In NB5-6T, seq mutants show both extra FMRFa and Eya cells. In NB3-3A, we also found more cells, consistent with over-proliferation also in this lineage. The question where these extra cells come from was answered by following the NB and daughters over time in the two lineages, which revealed that there was a failure in the type $\mathrm{I}>0$ switch in both these lineages. Next, we wanted to investigate if this happens globally in the VNC. The number of dividing NBs and GMCs were quantified, and showed that seq mutants indeed display general failure in the type I $>0$ switch. We could even find proliferative cells at a late embryonic stage, where there are normally no dividing cells. Overexpression of seq did not result in opposite phenotypes from mutants; instead we found that overexpression also induced more proliferation. This indicates that the levels of Seq are instructive for function.

Previous work has shown that the cell cycle genes $C y c E, E 2 f$, stg and dap are important for proliferation control in the VNC (Baumgardt, Karlsson et al. 2014), and we wanted to investigate if the failure in type $\mathrm{I}>0$ switch observed in $s e q$ mutants is due to that seq regulates the expression of these genes. Measuring the protein levels of these cell cycle genes revealed that especially $C y c E$ and $E 2 f$ are up-regulated in the seq mutant. Epistasis tests revealed that heterozygosity for $\mathrm{CycE}$ rescues the phenotype seen in the seq mutant on number of Eya cells, indicating that these genes interact genetically.

Since ttk and PRDMs have been indicated in Notch signaling, we wanted to study the relationship between seq and Notch signaling. For this we used a reporter transgene for one of the downstream targets of Notch signaling, $E(s p l) m 8-G F P$, and quantified its expression. In the seq mutant the expression of GFP was both activated in more NBs and expression levels were higher. Previous work has shown that expression of $E(\mathrm{spl}) \mathrm{m} 8$ gets gradually stronger prior to the switch from type I $>0$ (Ulvklo, Macdonald et al. 2012), so we asked whether the expression of seq conversely is down-regulated by surveying the expression of Seq over time. This revealed that the expression is indeed declining, and when reviewing whether Seq and 
$E(s p l) m 8-G F P$ are co-expressed in NBs, we found that during early development many NBs express only Seq, followed by co-expression of Seq and $E(s p l) m 8-G F P$, and at later development many NBs only express $E(s p l) m 8-G F P$. Epistasis tests showed that heterozygosity for $k u z$ could suppress the phenotype of the $s e q$ mutant with respect to number of Eya cells, and heterozygosity of seq could suppress the phenotype of the kuz mutant. To investigate the interaction between $s e q$ and Notch downstream targets we studied the effects on Eya cell numbers in embryos heterozygous for $s e q$ and $E(s p l)-C$, and found that neither alone affected the number of Eya cells generated, but combining seq and $E(s p l)-C$ generated an increased number of eya cells.

We attempted to perform ChIP for Seq, but unfortunately we did not succeed to bring down DNA. This may have helped to further elucidate the connection between Seq, Notch signaling and the cell cycle.

\section{Conclusions}

- Seq is involved in regulating the type $\mathrm{I}>0$ switch

- Seq represses expression of the cell cycle genes $C y c E$ and $E 2 f$

- There is an interplay between seq and Notch signaling to orchestrate the type $\mathrm{I}>0$ switch

- Seq levels are instructive 


\section{Paper III}

\section{Background}

The division mode of a NB and when it stops dividing is tightly regulated, but there are differences between individual NBs. It has been shown that the cell cycle genes $C y c E, E 2 f$, stg and dap are involved in regulating the type I $>0$ switch in NB5-6T, and that the late temporal factors cas and grh together with the Hox gene Antp, whose expression is activated during the latter part of lineage progression, regulate their expression (Baumgardt, Karlsson et al. 2014). In a forward genetic screen using FMRFa-eGFP as a reporter gene, a wor mutant was identified with reduced proliferation (Bivik, Bahrampour et al. 2015). There are thus factors that stop lineage progression and the result of the screen indicates that there are factors that drive lineage progression, so are there more early factors that drive proliferation, and how is lineage progression coordinated? Candidates for early drivers of proliferation are, besides wor and the other genes of the Sna family, the Sox family genes and the proneural genes that are known to be expressed in newly formed NBs (Dominguez and Campuzano 1993; Ashraf, Hu et al. 1999; Overton, Meadows et al. 2002; Ferrero, Fischer et al. 2014). Also, the earliest factors in the temporal cascade are potential regulators of proliferation (Brody and Odenwald 2000; Isshiki, Pearson et al. 2001). If these "early factors" promote type I divisions, then is the timely execution of the switch regulated by replacement of these early factors by the later, limiting genes? Do they all regulate the cell cycle genes to control proliferation, and do they regulate each other?

\section{Findings}

We first wanted to establish the expression patterns of the early factors during later stages of development, to see if there is a decline in their expression. For this, we studied their expression in NBs at different stages of development, and found that SoxN, wor, ase, $h b, \mathrm{Kr}$ and $N u b(P d m 2)$ are expressed in the NB at early stages but expression is down-regulated during later stages. We did the same mapping for the "late factors" cas, grh and Antp, and found the opposite; expression was initiated at later stages. All of these factors thereby show a temporal expression, where the early factors are gradually replaced by late factors.

What happens to proliferation if we mutate these early genes? We applied global mitotic index to the mutants and found that proliferation is decreased, especially NB proliferation. Estimating division mode revealed that mutants of wor, soxN or nub induce a premature type $\mathrm{I}>0$ switch. We also wanted to investigate the opposite; do we get increased proliferation if we express the genes ectopically? For this, we generated UAS constructs that were codon optimized and integrated by phiC31 landing site technology. We found that the temporal genes generated increased NB proliferation, but SoxN, wor and ase did not. We therefore generated UAS constructs with activation (VP16) or repressor domains (EnR), and found that Ase-Vp16, SoxN-EnR and wor-EnR triggered over-proliferation. Together, these results show that the early factors need to be down-regulated for the type I $>0$ switch and NB exit to occur at the precise time. 
The late factors are known to regulate the type $\mathrm{I}>0$ switch and the expression of the cell cycle genes $C y c E, E 2 f$, stg and dap known to be important for orchestrating the switch (Baumgardt, Karlsson et al. 2014). Do the early factors also regulate these cell cycle genes? We analyzed the expression of these in mutants and when over-expressing the early factors. For overexpression, the strongest phenotypes in the proliferation analysis above were observed in $h b$, $K r, n u b$, wor-EnR, ase-Vp16 and SoxN-EnR, so we focused on these. Indeed, the expression of cell cycle genes is affected upon these perturbations; the general picture is that these factors activate the expression of the cell cycle genes that drives the cell cycle and inhibit expression of dap that stops the cell cycle. This means that both the early and late factors regulate the expression of the cell cycle genes, but are they also regulating each other? For this, mutants and over-expression of early genes and mutants and over-expression of late genes were analyzed for expression of late genes and early genes, respectively. This showed that there are indeed regulatory interplays between the early and late genes. Though there are individual differences, a general picture is that the early factors activate the late factors, while the late factors repress the early factors.

Over-expressing the early factors generated increased proliferation, so what happens if we combine several early factors? We combined the pan-neural genes SoxN, wor and ase and the temporal genes $K r, h b$ and $n u b$, and found that both these combinations induced increased proliferation in the VNC. To elucidate the transcriptional background to this overproliferation, we expressed the combinations of pan-neural genes with $K r$, both with (Quad ${ }^{\mathrm{D}}$ ) and without (Quad) the activation/repressor domains. We performed transcriptome analysis and found changed expression of NB markers, cell cycle genes and temporal genes. The striking effects on proliferation and gene expression led us to the next question; can we induce

NB formation in another context? We turned to the wing disc where we expressed Quad $^{\mathrm{D}}$ and Quad, and this induced NBs in the wing disc that seems to undergo normal lineage progression, including asymmetric divisions. To test the potency of these combinations to induce ectopic formation of NBs, we combined the pan-neural genes with the early temporal factors (Hexa) and could induce ectopic NBs throughout the ectoderm.

\section{Conclusions}

- Proliferation is regulated both early and late in development, where early factors are gradually replaced by late factors

- SoxN, wor and Ase functions as temporal genes, with expression early in NB lineage progression, and declining expression as the NB progress through development

- The early factors are involved in regulating the type $\mathrm{I}>0$ switch

- The early factors regulate the expression of cell cycle genes

- The early and late factors cross-regulate each other, and the early factors are gradually replaced by late factors to coordinate a timely switch in division mode

- Over-expressing the early factors can induce ectopic formation of NBs, both in wing discs and in the ectoderm 


\section{Discussion and future challenges}

The work presented here has shown the importance of precise regulation of proliferation. The regulation of the switch in division mode has been investigated in the whole VNC and in more detail in NB5-6T and NB3-3A, and it would be interesting to explore the regulation in more detail in other lineages to see if the same regulatory mechanisms are applied in all lineages. Previous studies have pointed to regulators common to all NBs in regulating the switch and to terminate proliferation (Baumgardt, Karlsson et al. 2014), but lineages differ in their length and when the switch is scheduled. The progression from type I to type 0 and termination of proliferation occur at different time-points in different lineages, and at different times in the same NB in different segments. How is this regulated? Together with previous studies the data presented here shows that several programs integrate to execute the switch and termination of proliferation. One question that needs further studies is how this is regulated in different lineages at precise time-points. Previous studies has shown that late temporal genes, Hox genes and Notch signaling is involved in proliferation decisions (Ulvklo, Macdonald et al. 2012; Baumgardt, Karlsson et al. 2014), and the work presented here further contribute to explaining the regulation of these decisions. Different lineages terminate proliferation in different temporal windows and express different Hox genes, so are temporal factors and Hox genes applied in all lineages but different lineages use different temporal factors and Hox genes? The different programs shall be integrated to accomplish a function at a predetermined time, and by using both Notch signaling and temporal factors in combination with Hox genes can safeguard that important functions remain; perturbations in one program is compensated by the other programs. How does Notch integrate with temporal cascade and Hox to induce the switch? The switch occurs at different time-points in different lineages, so the timing of the switch must be at least partly intrinsically regulated. The Notch pathway and the temporal factors and Hox genes do not regulate each other, and over-expressing Notch with cas or Antp have combinatorial effects, so how can they act cooperatively to induce the switch in a timely manner? A remaining question is how Notch is activated in the NB prior to the switch.

Notch acts both as an oncogene and a tumor suppressor (Radtke and Raj 2003), and the twolevel mechanism shown here in the switch in division might contribute to explaining the diverse phenotypes observed when perturbing Notch signaling. This adds to the complexity of Notch signaling, not only being used in a context-specific manner (Koch, Lehal et al. 2013), but also being able to regulate the same genes in opposite ways. Elucidation of the two-level model presented here can aid in understanding why removing or over-expressing different players in the Notch pathway can generate different phenotypes. It shows that perturbing signaling at the receptor activation level generates an opposing phenotype than perturbing the target genes. This can also aid in the development of therapeutics, showing the importance of drugs which targets the correct level of the pathway. The fact that Notch signaling regulates the cell cycle genes opens up the possibility that it regulates proliferation in other contexts by regulating the cell cycle genes here as well. We also show that the $E$ (spl)-C genes have individual functions in different $\mathrm{NBs}$, and it would be interesting to elucidate the individual functions in more NBs to see if they are all differently used depending on NB. This might add 
to the NB identity genes established already before delamination, and the $E(s p l)-C$ genes might be a part of the identity genes used to uniquely specify the daughters of each single NB. To elucidate the roles of individual $E(s p l)-C$ genes we tried to make single transgenes, but due to their instability we could only detect stable expression when introducing a mutation in the phospho-degron site to inhibit degradation. This instability of the $\mathrm{E}(\mathrm{spl})-\mathrm{C}$ proteins prohibit the investigation of the expression of the single genes. Succeeding in this can map their expression patterns and help to analyze their individual functions. As discussed in paper II, they might have additive functions for timing of the switch; the more $E$ ( $s p l)-C$ genes expressed in a NB, the earlier the switch.

The results presented here show that seq has context dependent functions as we present a different interplay with Notch than previously presented in the wing disc. These context dependent functions are important to map, and the fact that seq and Notch seems to regulate the same target genes, the cell cycle genes, in NBs opens up the question if this is true also in other contexts. Elucidating the role of seq in the Notch pathway might help to clarify a common role for seq in different contexts. In addition, seq mutants show a phenotype that is slightly different from Notch mutants, suggesting additional roles in regulation of proliferation. Expression of seq shows that it is present in many cells in the CNS, indicating a general role during development. We have shown that there is an interplay with Notch, but has not managed to investigate if this connection is at the transcriptional level. We attempted to perform ChIP, but did not succeed to bring down DNA. For the future, it would be interesting to attempt to elucidate the transcriptional targets of Seq. Removing seq results in elevated levels of $E(\mathrm{spl}) m 8-E G F P$, so the Notch pathway is a potential target of Seq at the transcriptional level. PRDMs modify the chromatin state at promoters, and the role of seq in this regulation is another future challenge.

In the third paper we show that there are more proteins expressed in a temporal manner than those previously mapped. This indicates that the temporal cascade needs revision. Are there more factors expressed in this temporal manner, regulating the lineage progression? More temporal factors might help to fine-tune the identity of each NB, and regulate the division mode and rounds of divisions. This can elucidate which genes that acts as pan-neural genes to push proliferation and which that are uniquely required in different NBs to regulate their lineages. This can also generate a "NB cocktail" of genes that are required for the NB to progress through development, pushing proliferation. In addition, this could help in the hunt for genes necessary to wake up quiescent NBs. Knowledge in how to activate quiescent cells and force them to start proliferate is desirable; this could be used in regenerative medicine to replenish cells that are lost by using already existing cells within the tissue and instruct them towards an earlier developmental stage. In addition to re-activation of proliferation, knowledge is required regarding regulation of lineage size, both concerning which daughters each stem cell creates and when to terminate proliferation. For this, it is necessary to elucidate which factors that regulate proliferation, both driving and stopping, and which that regulate cell fate, and how this is coordinated. 


\section{References}

Adams, M. D., S. E. Celniker, et al. (2000). "The genome sequence of Drosophila melanogaster." Science 287(5461): 2185-2195.

Alberga, A., J. L. Boulay, et al. (1991). "The snail gene required for mesoderm formation in Drosophila is expressed dynamically in derivatives of all three germ layers." Development 111(4): 983-992.

Aleksic, J., E. Ferrero, et al. (2013). "The role of Dichaete in transcriptional regulation during Drosophila embryonic development." BMC Genomics 14: 861.

Andrews, H. K., N. Giagtzoglou, et al. (2009). "Sequoia regulates cell fate decisions in the external sensory organs of adult Drosophila." EMBO Rep 10(6): 636-641.

Ashraf, S. I., X. Hu, et al. (1999). "The mesoderm determinant snail collaborates with related zincfinger proteins to control Drosophila neurogenesis." EMBO J 18(22): 6426-6438.

Ashraf, S. I. and Y. T. Ip (2001). "The Snail protein family regulates neuroblast expression of inscuteable and string, genes involved in asymmetry and cell division in Drosophila." Development 128(23): 4757-4767.

Atwood, S. X. and K. E. Prehoda (2009). "aPKC phosphorylates Miranda to polarize fate determinants during neuroblast asymmetric cell division." Curr Biol 19(9): 723-729.

Badenhorst, P. (2001). "Tramtrack controls glial number and identity in the Drosophila embryonic CNS." Development 128(20): 4093-4101.

Bardin, A. J., R. Le Borgne, et al. (2004). "Asymmetric localization and function of cell-fate determinants: a fly's view." Curr Opin Neurobiol 14(1): 6-14.

Bardin, A. J. and F. Schweisguth (2006). "Bearded family members inhibit Neuralized-mediated endocytosis and signaling activity of Delta in Drosophila." Dev Cell 10(2): 245-255.

Baumgardt, M., D. Karlsson, et al. (2014). "Global programmed switch in neural daughter cell proliferation mode triggered by a temporal gene cascade." Dev Cell 30(2): 192-208.

Baumgardt, M., D. Karlsson, et al. (2009). "Neuronal subtype specification within a lineage by opposing temporal feed-forward loops." Cell 139(5): 969-982.

Bayraktar, O. A. and C. Q. Doe (2013). "Combinatorial temporal patterning in progenitors expands neural diversity." Nature 498(7455): 449-455.

Bello, B. C., F. Hirth, et al. (2003). "A pulse of the Drosophila Hox protein Abdominal-A schedules the end of neural proliferation via neuroblast apoptosis." Neuron 37(2): 209-219.

Bello, B. C., N. Izergina, et al. (2008). "Amplification of neural stem cell proliferation by intermediate progenitor cells in Drosophila brain development." Neural Dev 3: 5 .

Berdnik, D., T. Torok, et al. (2002). "The endocytic protein alpha-Adaptin is required for numbmediated asymmetric cell division in Drosophila." Dev Cell 3(2): 221-231.

Bertrand, N., D. S. Castro, et al. (2002). "Proneural genes and the specification of neural cell types." Nat Rev Neurosci 3(7): 517-530.

Betschinger, J., K. Mechtler, et al. (2006). "Asymmetric segregation of the tumor suppressor brat regulates self-renewal in Drosophila neural stem cells." Cell 124(6): 1241-1253.

Bivik, C., S. Bahrampour, et al. (2015). "Novel Genes Involved in Controlling Specification of Drosophila FMRFamide Neuropeptide Cells." Genetics 200(4): 1229-1244.

Bongso, A. and E. H. Lee (2005). Stem cells : from bench to bedside. Singapore ; Hackensack, NJ ; London, World Scientific.

Boone, J. Q. and C. Q. Doe (2008). "Identification of Drosophila type II neuroblast lineages containing transit amplifying ganglion mother cells." Dev Neurobiol 68(9): 1185-1195.

Bowman, S. K., V. Rolland, et al. (2008). "The tumor suppressors Brat and Numb regulate transitamplifying neuroblast lineages in Drosophila." Dev Cell 14(4): 535-546.

Brand, M., A. P. Jarman, et al. (1993). "asense is a Drosophila neural precursor gene and is capable of initiating sense organ formation." Development 119(1): 1-17.

Bray, S. (1998). "Notch signalling in Drosophila: three ways to use a pathway." Semin Cell Dev Biol 9(6): 591-597. 
Bray, S. and M. Furriols (2001). "Notch pathway: making sense of suppressor of hairless." Curr Biol 11(6): R217-221.

Bray, S. J. (2006). "Notch signalling: a simple pathway becomes complex." Nat Rev Mol Cell Biol 7(9): 678-689.

Brenman, J. E., F. B. Gao, et al. (2001). "Sequoia, a tramtrack-related zinc finger protein, functions as a pan-neural regulator for dendrite and axon morphogenesis in Drosophila." Dev Cell 1(5): 667-677.

Broadus, J., J. B. Skeath, et al. (1995). "New neuroblast markers and the origin of the aCC/pCC neurons in the Drosophila central nervous system." Mech Dev 53(3): 393-402.

Brody, T. and W. F. Odenwald (2000). "Programmed transformations in neuroblast gene expression during Drosophila CNS lineage development." Dev Biol 226(1): 34-44.

Budirahardja, Y. and P. Gonczy (2009). "Coupling the cell cycle to development." Development 136(17): 2861-2872.

Buescher, M., F. S. Hing, et al. (2002). "Formation of neuroblasts in the embryonic central nervous system of Drosophila melanogaster is controlled by SoxNeuro." Development 129(18): 41934203.

Cabernard, C. and C. Q. Doe (2009). "Apical/basal spindle orientation is required for neuroblast homeostasis and neuronal differentiation in Drosophila." Dev Cell 17(1): 134-141.

Cabrera, C. V. and M. C. Alonso (1991). "Transcriptional activation by heterodimers of the achaetescute and daughterless gene products of Drosophila." Embo J 10(10): 2965-2973.

Cai, Y., W. Chia, et al. (2001). "A family of snail-related zinc finger proteins regulates two distinct and parallel mechanisms that mediate Drosophila neuroblast asymmetric divisions." EMBO J 20(7): 1704-1714.

Cai, Y., F. Yu, et al. (2003). "Apical complex genes control mitotic spindle geometry and relative size of daughter cells in Drosophila neuroblast and pI asymmetric divisions." Cell 112(1): 51-62.

Campbell, S. D., F. Sprenger, et al. (1995). "Drosophila Wee1 kinase rescues fission yeast from mitotic catastrophe and phosphorylates Drosophila Cdc2 in vitro." Mol Biol Cell 6(10): 13331347.

Cashio, P., T. V. Lee, et al. (2005). "Genetic control of programmed cell death in Drosophila melanogaster." Semin Cell Dev Biol 16(2): 225-235.

Cau, E. and P. Blader (2009). "Notch activity in the nervous system: to switch or not switch?" Neural Dev 4: 36.

Caussinus, E. and C. Gonzalez (2005). "Induction of tumor growth by altered stem-cell asymmetric division in Drosophila melanogaster." Nat Genet 37(10): 1125-1129.

Cayouette, M. and M. Raff (2002). "Asymmetric segregation of Numb: a mechanism for neural specification from Drosophila to mammals." Nat Neurosci 5(12): 1265-1269.

Chang, K. C., C. Wang, et al. (2012). "Balancing self-renewal and differentiation by asymmetric division: insights from brain tumor suppressors in Drosophila neural stem cells." Bioessays 34(4): 301-310.

Chia, N. Y., Y. S. Chan, et al. (2010). "A genome-wide RNAi screen reveals determinants of human embryonic stem cell identity." Nature 468(7321): 316-320.

Chitnis, A. (2006). "Why is delta endocytosis required for effective activation of notch?" Dev Dyn 235(4): 886-894.

Choksi, S. P., T. D. Southall, et al. (2006). "Prospero acts as a binary switch between self-renewal and differentiation in Drosophila neural stem cells." Dev Cell 11(6): 775-789.

Cleary, M. D. and C. Q. Doe (2006). "Regulation of neuroblast competence: multiple temporal identity factors specify distinct neuronal fates within a single early competence window." Genes Dev 20(4): 429-434.

Cremazy, F., P. Berta, et al. (2000). "Sox neuro, a new Drosophila Sox gene expressed in the developing central nervous system." Mech Dev 93(1-2): 215-219.

Culi, J. and J. Modolell (1998). "Proneural gene self-stimulation in neural precursors: an essential mechanism for sense organ development that is regulated by Notch signaling." Genes Dev 12(13): 2036-2047.

Dang-Nguyen, T. Q. and M. E. Torres-Padilla (2015). "How cells build totipotency and pluripotency: nuclear, chromatin and transcriptional architecture." Curr Opin Cell Biol 34: 9-15. 
Datar, S. A., H. W. Jacobs, et al. (2000). "The Drosophila cyclin D-Cdk4 complex promotes cellular growth." EMBO J 19(17): 4543-4554.

Davidson, E. H. (2010). "Emerging properties of animal gene regulatory networks." Nature 468(7326): 911-920.

de Celis, J. F., J. de Celis, et al. (1996). "Functional relationships between Notch, Su(H) and the bHLH genes of the $\mathrm{E}(\mathrm{spl})$ complex: the $\mathrm{E}(\mathrm{spl})$ genes mediate only a subset of Notch activities during imaginal development." Development 122(9): 2719-2728.

de Nooij, J. C., M. A. Letendre, et al. (1996). "A cyclin-dependent kinase inhibitor, Dacapo, is necessary for timely exit from the cell cycle during Drosophila embryogenesis." Cell 87(7): 1237-1247.

Delidakis, C., A. Preiss, et al. (1991). "Two genetically and molecularly distinct functions involved in early neurogenesis reside within the Enhancer of split locus of Drosophila melanogaster." Genetics 129(3): 803-823.

Desai, A. R. and S. K. McConnell (2000). "Progressive restriction in fate potential by neural progenitors during cerebral cortical development." Development 127(13): 2863-2872.

Doe, C. Q. (1992). "Molecular markers for identified neuroblasts and ganglion mother cells in the Drosophila central nervous system." Development 116(4): 855-863.

Doe, C. Q. (2008). "Neural stem cells: balancing self-renewal with differentiation." Development 135(9): 1575-1587.

Dominguez, M. and S. Campuzano (1993). "asense, a member of the Drosophila achaete-scute complex, is a proneural and neural differentiation gene." EMBO J 12(5): 2049-2060.

Duronio, R. J., P. C. Bonnette, et al. (1998). "Mutations of the Drosophila dDP, dE2F, and cyclin E genes reveal distinct roles for the E2F-DP transcription factor and cyclin E during the G1-S transition." Mol Cell Biol 18(1): 141-151.

Duronio, R. J., A. Brook, et al. (1996). "E2F-induced S phase requires cyclin E." Genes Dev 10(19): 2505-2513.

Dyson, N. (1998). "The regulation of E2F by pRB-family proteins." Genes Dev 12(15): 2245-2262.

Edgar, B. A. and P. H. O'Farrell (1990). "The three postblastoderm cell cycles of Drosophila embryogenesis are regulated in G2 by string." Cell 62(3): 469-480.

Ferrero, E., B. Fischer, et al. (2014). "SoxNeuro orchestrates central nervous system specification and differentiation in Drosophila and is only partially redundant with Dichaete." Genome Biol 15(5): R74.

Fichelson, P., A. Audibert, et al. (2005). "Cell cycle and cell-fate determination in Drosophila neural cell lineages." Trends Genet 21(7): 413-420.

Fish, J. L., C. Dehay, et al. (2008). "Making bigger brains-the evolution of neural-progenitor-cell division." J Cell Sci 121(Pt 17): 2783-2793.

Foley, E., P. H. O'Farrell, et al. (1999). "Rux is a cyclin-dependent kinase inhibitor (CKI) specific for mitotic cyclin-Cdk complexes." Curr Biol 9(23): 1392-1402.

Fortini, M. E. (2009). "Notch signaling: the core pathway and its posttranslational regulation." Dev Cell 16(5): 633-647.

Fortini, M. E. and S. Artavanis-Tsakonas (1994). "The suppressor of hairless protein participates in notch receptor signaling." Cell 79(2): 273-282.

Franco, S. J. and U. Muller (2013). "Shaping our minds: stem and progenitor cell diversity in the mammalian neocortex." Neuron 77(1): 19-34.

Frolov, M. V., D. S. Huen, et al. (2001). "Functional antagonism between E2F family members." Genes Dev 15(16): 2146-2160.

Fryer, C. J., E. Lamar, et al. (2002). "Mastermind mediates chromatin-specific transcription and turnover of the Notch enhancer complex." Genes Dev 16(11): 1397-1411.

Fryer, C. J., J. B. White, et al. (2004). "Mastermind recruits CycC:CDK8 to phosphorylate the Notch ICD and coordinate activation with turnover." Mol Cell 16(4): 509-520.

Gao, F. B., J. E. Brenman, et al. (1999). "Genes regulating dendritic outgrowth, branching, and routing in Drosophila." Genes Dev 13(19): 2549-2561.

Garces, A. and S. Thor (2006). "Specification of Drosophila aCC motoneuron identity by a genetic cascade involving even-skipped, grain and zfh1." Development 133(8): 1445-1455. 
Ghosh, L. and S. Jessberger (2013). "Supersize me-new insights into cortical expansion and gyration of the mammalian brain." EMBO J 32(13): 1793-1795.

Giagtzoglou, N., P. Alifragis, et al. (2003). "Two modes of recruitment of E(spl) repressors onto target genes." Development 130(2): 259-270.

Gonzalez, F., S. Romani, et al. (1989). "Molecular analysis of the asense gene, a member of the achaete-scute complex of Drosophila melanogaster, and its novel role in optic lobe development." Embo J 8(12): 3553-3562.

Gotz, M. and W. B. Huttner (2005). "The cell biology of neurogenesis." Nat Rev Mol Cell Biol 6(10): 777-788.

Grosskortenhaus, R., B. J. Pearson, et al. (2005). "Regulation of temporal identity transitions in Drosophila neuroblasts." Dev Cell 8(2): 193-202.

Gu, Y., N. A. Hukriede, et al. (1995). "Serrate expression can functionally replace Delta activity during neuroblast segregation in the Drosophila embryo." Development 121(3): 855-865.

Guillemot, F. (1999). "Vertebrate bHLH genes and the determination of neuronal fates." Exp Cell Res 253(2): 357-364.

Guillemot, F. (2007). "Spatial and temporal specification of neural fates by transcription factor codes." Development 134(21): 3771-3780.

Guo, M., E. Bier, et al. (1995). "tramtrack acts downstream of numb to specify distinct daughter cell fates during asymmetric cell divisions in the Drosophila PNS." Neuron 14(5): 913-925.

Guo, M., L. Y. Jan, et al. (1996). "Control of daughter cell fates during asymmetric division: interaction of Numb and Notch." Neuron 17(1): 27-41.

Hales, K. G., C. A. Korey, et al. (2015). "Genetics on the Fly: A Primer on the Drosophila Model System." Genetics 201(3): 815-842.

Hartenstein, V. and A. Wodarz (2013). "Initial neurogenesis in Drosophila." Wiley Interdiscip Rev Dev Biol 2(5): 701-721.

Heitzler, P., M. Bourouis, et al. (1996). "Genes of the Enhancer of split and achaete-scute complexes are required for a regulatory loop between Notch and Delta during lateral signalling in Drosophila." Development 122(1): 161-171.

Hemavathy, K., S. I. Ashraf, et al. (2000). "Snail/slug family of repressors: slowly going into the fast lane of development and cancer." Gene 257(1): 1-12.

Hohenauer, T. and A. W. Moore (2012). "The Prdm family: expanding roles in stem cells and development." Development 139(13): 2267-2282.

Homem, C. C. and J. A. Knoblich (2012). "Drosophila neuroblasts: a model for stem cell biology." Development 139(23): 4297-4310.

Hori, K., A. Sen, et al. (2013). "Notch signaling at a glance." J Cell Sci 126(Pt 10): 2135-2140.

Hutterer, A. and J. A. Knoblich (2005). "Numb and alpha-Adaptin regulate Sanpodo endocytosis to specify cell fate in Drosophila external sensory organs." EMBO Rep 6(9): 836-842.

Ilagan, M. X. and R. Kopan (2007). "SnapShot: notch signaling pathway." Cell 128(6): 1246.

Ip, Y. T., M. Levine, et al. (1994). "Neurogenic expression of snail is controlled by separable CNS and PNS promoter elements." Development 120(1): 199-207.

Isshiki, T., B. Pearson, et al. (2001). "Drosophila neuroblasts sequentially express transcription factors which specify the temporal identity of their neuronal progeny." Cell 106(4): 511-521.

Itoh, M., C. H. Kim, et al. (2003). "Mind bomb is a ubiquitin ligase that is essential for efficient activation of Notch signaling by Delta." Dev Cell 4(1): 67-82.

Izumi, Y., N. Ohta, et al. (2006). "Drosophila Pins-binding protein Mud regulates spindle-polarity coupling and centrosome organization." Nat Cell Biol 8(6): 586-593.

Izumi, Y., N. Ohta, et al. (2004). "Differential functions of G protein and Baz-aPKC signaling pathways in Drosophila neuroblast asymmetric division." J Cell Biol 164(5): 729-738.

Jacobs, H. W., J. A. Knoblich, et al. (1998). "Drosophila Cyclin B3 is required for female fertility and is dispensable for mitosis like Cyclin B." Genes Dev 12(23): 3741-3751.

Jacobsen, T. L., K. Brennan, et al. (1998). "Cis-interactions between Delta and Notch modulate neurogenic signalling in Drosophila." Development 125(22): 4531-4540.

Jennings, B., A. Preiss, et al. (1994). "The Notch signalling pathway is required for Enhancer of split bHLH protein expression during neurogenesis in the Drosophila embryo." Development 120(12): 3537-3548. 
Jimenez, F. and J. A. Campos-Ortega (1990). "Defective neuroblast commitment in mutants of the achaete-scute complex and adjacent genes of D. melanogaster." Neuron 5(1): 81-89.

Kamachi, Y. and H. Kondoh (2013). "Sox proteins: regulators of cell fate specification and differentiation." Development 140(20): 4129-4144.

Kang, E., Z. Wen, et al. (2016). "Adult Neurogenesis and Psychiatric Disorders." Cold Spring Harb Perspect Biol 8(9).

Kang, K. H. and H. Reichert (2015). "Control of neural stem cell self-renewal and differentiation in Drosophila." Cell Tissue Res 359(1): 33-45.

Karcavich, R. and C. Q. Doe (2005). "Drosophila neuroblast 7-3 cell lineage: a model system for studying programmed cell death, Notch/Numb signaling, and sequential specification of ganglion mother cell identity." J Comp Neurol 481(3): 240-251.

Karcavich, R. E. (2005). "Generating neuronal diversity in the Drosophila central nervous system: a view from the ganglion mother cells." Dev Dyn 232(3): 609-616.

Karlsson, D., M. Baumgardt, et al. (2010). "Segment-specific neuronal subtype specification by the integration of anteroposterior and temporal cues." PLoS Biol 8(5): e1000368.

Kinameri, E., T. Inoue, et al. (2008). "Prdm proto-oncogene transcription factor family expression and interaction with the Notch-Hes pathway in mouse neurogenesis." PLoS One 3(12): e3859.

Knoblich, J. A. (2008). "Mechanisms of Asymmetric Stem Cell Division." Cell 132(4): 583-597.

Knoblich, J. A. and C. F. Lehner (1993). "Synergistic action of Drosophila cyclins A and B during the G2-M transition." EMBO J 12(1): 65-74.

Knoblich, J. A., K. Sauer, et al. (1994). "Cyclin E controls S phase progression and its downregulation during Drosophila embryogenesis is required for the arrest of cell proliferation." Cell 77(1): 107-120.

Knust, E., H. Schrons, et al. (1992). "Seven genes of the Enhancer of split complex of Drosophila melanogaster encode helix-loop-helix proteins." Genetics 132(2): 505-518.

Koch, U., R. Lehal, et al. (2013). "Stem cells living with a Notch." Development 140(4): 689-704.

Kohwi, M. and C. Q. Doe (2013). "Temporal fate specification and neural progenitor competence during development." Nat Rev Neurosci 14(12): 823-838.

Kopan, R. (2012). "Notch signaling." Cold Spring Harb Perspect Biol 4(10).

Kopan, R. and M. X. Ilagan (2009). "The canonical Notch signaling pathway: unfolding the activation mechanism." Cell 137(2): 216-233.

Kramatschek, B. and J. A. Campos-Ortega (1994). "Neuroectodermal transcription of the Drosophila neurogenic genes $\mathrm{E}(\mathrm{spl})$ and HLH-m5 is regulated by proneural genes." Development $\mathbf{1 2 0}(4)$ : 815-826.

Krejci, A. and S. Bray (2007). "Notch activation stimulates transient and selective binding of $\mathrm{Su}(\mathrm{H}) / \mathrm{CSL}$ to target enhancers." Genes Dev 21(11): 1322-1327.

Kulkarni, A., D. Ertekin, et al. (2016). "Birth order dependent growth cone segregation determines synaptic layer identity in the Drosophila visual system." Elife 5: e13715.

Kunisch, M., M. Haenlin, et al. (1994). "Lateral inhibition mediated by the Drosophila neurogenic gene delta is enhanced by proneural proteins." Proc Natl Acad Sci U S A 91(21): 1013910143.

Lai, E. C. (2002). "Protein degradation: four E3s for the notch pathway." Curr Biol 12(2): R74-78.

Lai, S. L. and C. Q. Doe (2014). "Transient nuclear Prospero induces neural progenitor quiescence." Elife 3.

Lai, S. L., M. R. Miller, et al. (2012). "The Snail family member Worniu is continuously required in neuroblasts to prevent Elav-induced premature differentiation." Dev Cell 23(4): 849-857.

Lane, M. E., M. Elend, et al. (2000). "A screen for modifiers of cyclin E function in Drosophila melanogaster identifies $\mathrm{Cdk} 2$ mutations, revealing the insignificance of putative phosphorylation sites in Cdk2." Genetics 155(1): 233-244.

Lane, M. E., K. Sauer, et al. (1996). "Dacapo, a cyclin-dependent kinase inhibitor, stops cell proliferation during Drosophila development." Cell 87(7): 1225-1235.

Larochelle, S., J. Pandur, et al. (1998). "Cdk7 is essential for mitosis and for in vivo Cdk-activating kinase activity." Genes Dev 12(3): 370-381.

Le Borgne, R. and F. Schweisguth (2003). "Notch signaling: endocytosis makes delta signal better." Curr Biol 13(7): R273-275. 
Le Borgne, R. and F. Schweisguth (2003). "Unequal segregation of Neuralized biases Notch activation during asymmetric cell division." Dev Cell 5(1): 139-148.

Lecourtois, M. and F. Schweisguth (1995). "The neurogenic suppressor of hairless DNA-binding protein mediates the transcriptional activation of the enhancer of split complex genes triggered by Notch signaling." Genes Dev 9(21): 2598-2608.

Lee, C. Y., R. O. Andersen, et al. (2006). "Drosophila Aurora-A kinase inhibits neuroblast selfrenewal by regulating aPKC/Numb cortical polarity and spindle orientation." Genes Dev 20(24): 3464-3474.

Lee, C. Y., B. D. Wilkinson, et al. (2006). "Brat is a Miranda cargo protein that promotes neuronal differentiation and inhibits neuroblast self-renewal." Dev Cell 10(4): 441-449.

Lee, J. E. (1997). "Basic helix-loop-helix genes in neural development." Curr Opin Neurobiol 7(1): 13-20.

Lehner, C. F. and P. H. O'Farrell (1989). "Expression and function of Drosophila cyclin A during embryonic cell cycle progression." Cell 56(6): 957-968.

Li, L. and H. Vaessin (2000). "Pan-neural Prospero terminates cell proliferation during Drosophila neurogenesis." Genes Dev 14(2): 147-151.

Li, R. (2013). "The art of choreographing asymmetric cell division." Dev Cell 25(5): 439-450.

Li, X., Z. Chen, et al. (2013). "Temporal patterning of neural progenitors in Drosophila." Curr Top Dev Biol 105: 69-96.

Li, X., T. Erclik, et al. (2013). "Temporal patterning of Drosophila medulla neuroblasts controls neural fates." Nature 498(7455): 456-462.

Li, Y. and N. E. Baker (2004). "The roles of cis-inactivation by Notch ligands and of neuralized during eye and bristle patterning in Drosophila." BMC Dev Biol 4: 5 .

Ligoxygakis, P., S. J. Bray, et al. (1999). "Ectopic expression of individual E(spl) genes has differential effects on different cell fate decisions and underscores the biphasic requirement for notch activity in wing margin establishment in Drosophila." Development 126(10): 22052214.

Louvi, A. and S. Artavanis-Tsakonas (2012). "Notch and disease: a growing field." Semin Cell Dev Biol 23(4): 473-480.

Lu, B., M. Rothenberg, et al. (1998). "Partner of Numb colocalizes with Numb during mitosis and directs Numb asymmetric localization in Drosophila neural and muscle progenitors." Cell 95(2): 225-235.

Lundell, M. J., H. K. Lee, et al. (2003). "The regulation of apoptosis by Numb/Notch signaling in the serotonin lineage of Drosophila." Development 130(17): 4109-4121.

Ma, Y., E. L. Niemitz, et al. (1998). "Gene regulatory functions of Drosophila fish-hook, a high mobility group domain Sox protein." Mech Dev 73(2): 169-182.

Martin-Bermudo, M. D., C. Martinez, et al. (1991). "Distribution and function of the lethal of scute gene product during early neurogenesis in Drosophila." Development 113(2): 445-454.

Maurange, C., L. Cheng, et al. (2008). "Temporal transcription factors and their targets schedule the end of neural proliferation in Drosophila." Cell 133(5): 891-902.

Maurange, C. and A. P. Gould (2005). "Brainy but not too brainy: starting and stopping neuroblast divisions in Drosophila." Trends Neurosci 28(1): 30-36.

Miguel-Aliaga, I., D. W. Allan, et al. (2004). "Independent roles of the dachshund and eyes absent genes in BMP signaling, axon pathfinding and neuronal specification." Development 131(23): 5837-5848.

Miller, A. C., E. L. Lyons, et al. (2009). "cis-Inhibition of Notch by endogenous Delta biases the outcome of lateral inhibition." Curr Biol 19(16): 1378-1383.

Moberg, K. H., A. Mukherjee, et al. (2004). "The Drosophila F box protein archipelago regulates dMyc protein levels in vivo." Curr Biol 14(11): 965-974.

Morgan, T. H. (1910). "Sex Limited Inheritance in Drosophila." Science 32(812): 120-122.

Muotri, A. R. and F. H. Gage (2006). "Generation of neuronal variability and complexity." Nature 441(7097): 1087-1093.

Nakao, K. and J. A. Campos-Ortega (1996). "Persistent expression of genes of the enhancer of split complex suppresses neural development in Drosophila." Neuron 16(2): 275-286. 
Nambu, P. A. and J. R. Nambu (1996). "The Drosophila fish-hook gene encodes a HMG domain protein essential for segmentation and CNS development." Development 122(11): 3467-3475.

Nichols, J. T., A. Miyamoto, et al. (2007). "Notch signaling--constantly on the move." Traffic 8(8): 959-969.

Nieto, M. A. (2002). "The snail superfamily of zinc-finger transcription factors." Nat Rev Mol Cell Biol 3(3): 155-166.

Novotny, T., R. Eiselt, et al. (2002). "Hunchback is required for the specification of the early sublineage of neuroblast 7-3 in the Drosophila central nervous system." Development 129(4): 1027-1036.

O'Connor-Giles, K. M. and J. B. Skeath (2003). "Numb inhibits membrane localization of Sanpodo, a four-pass transmembrane protein, to promote asymmetric divisions in Drosophila." Dev Cell 5(2): 231-243.

Oellers, N., M. Dehio, et al. (1994). "bHLH proteins encoded by the Enhancer of split complex of Drosophila negatively interfere with transcriptional activation mediated by proneural genes." Mol Gen Genet 244(5): 465-473.

Overton, P. M., L. A. Meadows, et al. (2002). "Evidence for differential and redundant function of the Sox genes Dichaete and SoxN during CNS development in Drosophila." Development 129(18): 4219-4228.

Paridaen, J. T. and W. B. Huttner (2014). "Neurogenesis during development of the vertebrate central nervous system." EMBO Rep 15(4): 351-364.

Paroush, Z., R. L. Finley, Jr., et al. (1994). "Groucho is required for Drosophila neurogenesis, segmentation, and sex determination and interacts directly with hairy-related bHLH proteins." Cell 79(5): 805-815.

Pearson, B. J. and C. Q. Doe (2003). "Regulation of neuroblast competence in Drosophila." Nature 425(6958): 624-628.

Peterson, C., G. E. Carney, et al. (2002). "reaper is required for neuroblast apoptosis during Drosophila development." Development 129(6): 1467-1476.

Petrovic, M. and T. Hummel (2008). "Temporal identity in axonal target layer recognition." Nature 456(7223): 800-803.

Phochanukul, N. and S. Russell (2010). "No backbone but lots of Sox: Invertebrate Sox genes." Int J Biochem Cell Biol 42(3): 453-464.

Prokop, A., S. Bray, et al. (1998). "Homeotic regulation of segment-specific differences in neuroblast numbers and proliferation in the Drosophila central nervous system." Mech Dev 74(1-2): 99110 .

Radtke, F. and K. Raj (2003). "The role of Notch in tumorigenesis: oncogene or tumour suppressor?" Nat Rev Cancer 3(10): 756-767.

Roark, M., M. A. Sturtevant, et al. (1995). "scratch, a pan-neural gene encoding a zinc finger protein related to snail, promotes neuronal development." Genes Dev 9(19): 2384-2398.

Rogulja-Ortmann, A., S. Renner, et al. (2008). "Antagonistic roles for Ultrabithorax and Antennapedia in regulating segment-specific apoptosis of differentiated motoneurons in the Drosophila embryonic central nervous system." Development 135(20): 3435-3445.

Rubin, G. M., M. D. Yandell, et al. (2000). "Comparative genomics of the eukaryotes." Science 287(5461): 2204-2215.

Sanchez-Soriano, N. and S. Russell (2000). "Regulatory mutations of the Drosophila Sox gene Dichaete reveal new functions in embryonic brain and hindgut development." Dev Biol 220(2): 307-321.

Schaefer, M., A. Shevchenko, et al. (2000). "A protein complex containing Inscuteable and the Galpha-binding protein Pins orients asymmetric cell divisions in Drosophila." Curr Biol 10(7): 353-362.

Schmid, A., A. Chiba, et al. (1999). "Clonal analysis of Drosophila embryonic neuroblasts: neural cell types, axon projections and muscle targets." Development 126(21): 4653-4689.

Schmidt, H., C. Rickert, et al. (1997). "The embryonic central nervous system lineages of Drosophila melanogaster. II. Neuroblast lineages derived from the dorsal part of the neuroectoderm." Dev Biol 189(2): 186-204. 
Schoenfeld, T. J. and H. A. Cameron (2015). "Adult neurogenesis and mental illness." Neuropsychopharmacology 40(1): 113-128.

Schrons, H., E. Knust, et al. (1992). "The Enhancer of split complex and adjacent genes in the 96F region of Drosophila melanogaster are required for segregation of neural and epidermal progenitor cells." Genetics 132(2): 481-503.

Schweisguth, F. (2004). "Regulation of notch signaling activity." Curr Biol 14(3): R129-138.

Seugnet, L., P. Simpson, et al. (1997). "Requirement for dynamin during Notch signaling in Drosophila neurogenesis." Dev Biol 192(2): 585-598.

Shackleton, M. (2010). "Normal stem cells and cancer stem cells: similar and different." Semin Cancer Biol 20(2): 85-92.

Shen, C. P., L. Y. Jan, et al. (1997). "Miranda is required for the asymmetric localization of Prospero during mitosis in Drosophila." Cell 90(3): 449-458.

Shen, S. P., J. Aleksic, et al. (2013). "Identifying targets of the Sox domain protein Dichaete in the Drosophila CNS via targeted expression of dominant negative proteins." BMC Dev Biol 13: 1.

Skeath, J. B. and S. B. Carroll (1992). "Regulation of proneural gene expression and cell fate during neuroblast segregation in the Drosophila embryo." Development 114(4): 939-946.

Skeath, J. B. and C. Q. Doe (1998). "Sanpodo and Notch act in opposition to Numb to distinguish sibling neuron fates in the Drosophila CNS." Development 125(10): 1857-1865.

Skeath, J. B. and S. Thor (2003). "Genetic control of Drosophila nerve cord development." Curr Opin Neurobiol 13(1): 8-15.

Sousa-Nunes, R., L. Y. Cheng, et al. (2010). "Regulating neural proliferation in the Drosophila CNS." Curr Opin Neurobiol 20(1): 50-57.

Southall, T. D. and A. H. Brand (2009). "Neural stem cell transcriptional networks highlight genes essential for nervous system development." EMBO J 28(24): 3799-3807.

Spitz, F. and E. E. Furlong (2012). "Transcription factors: from enhancer binding to developmental control." Nat Rev Genet 13(9): 613-626.

Stevaux, O. and N. J. Dyson (2002). "A revised picture of the E2F transcriptional network and RB function." Curr Opin Cell Biol 14(6): 684-691.

Tan, Y., M. Yamada-Mabuchi, et al. (2011). "Coordinated expression of cell death genes regulates neuroblast apoptosis." Development 138(11): 2197-2206.

Technau, G. M., C. Berger, et al. (2006). "Generation of cell diversity and segmental pattern in the embryonic central nervous system of Drosophila." Developmental Dynamics 235(4): 861-869.

Tsuji, T., E. Hasegawa, et al. (2008). "Neuroblast entry into quiescence is regulated intrinsically by the combined action of spatial Hox proteins and temporal identity factors." Development 135(23): 3859-3869.

Ulvklo, C., R. Macdonald, et al. (2012). "Control of neuronal cell fate and number by integration of distinct daughter cell proliferation modes with temporal progression." Development 139(4): 678-689.

Vaessin, H., M. Brand, et al. (1994). "daughterless is essential for neuronal precursor differentiation but not for initiation of neuronal precursor formation in Drosophila embryo." Development 120(4): 935-945.

Wang, H., G. W. Somers, et al. (2006). "Aurora-A acts as a tumor suppressor and regulates selfrenewal of Drosophila neuroblasts." Genes Dev 20(24): 3453-3463.

Wech, I., S. Bray, et al. (1999). "Distinct expression patterns of different enhancer of split bHLH genes during embryogenesis of Drosophila melanogaster." Dev Genes Evol 209(6): 370-375.

Vermeulen, K., D. R. Van Bockstaele, et al. (2003). "The cell cycle: a review of regulation, deregulation and therapeutic targets in cancer." Cell Prolif 36(3): 131-149.

Wirtz-Peitz, F., T. Nishimura, et al. (2008). "Linking cell cycle to asymmetric division: Aurora-A phosphorylates the Par complex to regulate Numb localization." Cell 135(1): 161-173.

Vodermaier, H. C. (2004). "APC/C and SCF: controlling each other and the cell cycle." Curr Biol 14(18): R787-796.

Wu, P.-S., B. Egger, et al. (2008). "Asymmetric stem cell division: Lessons from Drosophila." Seminars in Cell \& Developmental Biology 19(3): 283-293. 
Zander, M. A., S. E. Burns, et al. (2014). "Snail coordinately regulates downstream pathways to control multiple aspects of Mammalian neural precursor development." J Neurosci 34(15): 5164-5175.

Zhao, G., G. Boekhoff-Falk, et al. (2007). "Linking pattern formation to cell-type specification: Dichaete and Ind directly repress achaete gene expression in the Drosophila CNS." Proc Natl Acad Sci U S A 104(10): 3847-3852.

Zhao, G. and J. B. Skeath (2002). "The Sox-domain containing gene Dichaete/fish-hook acts in concert with vnd and ind to regulate cell fate in the Drosophila neuroectoderm." Development 129(5): 1165-1174. 
References 


\section{Acknowledgements}

I am so grateful for all the support, encouragement and help I have been given from everyone during my time as a PhD student, and especially I would like to thank:

First of all, I would like to thank my supervisor Stefan Thor for all the support during this thesis. You have the ability to inspire that can make something that seems impossible to feel like nothing. No question asked is too small or too simple, and I appreciate that you have taken the time to discuss and guiding me through this work. Your enthusiasm for science, knowledge and encouragement has made a visit to your office a guarantee for new energy to do more experiments.

Thank you to my co-supervisor Jan-Ingvar Jönsson. It has been interesting to hear about what happens in the scientific world, and it has felt reassuring to know you are there if needed.

Thank you to Thor-lab members, present and past. I am certain my time would not have been this fun without you guys. A special thanks to Caroline Bivik for not only working together on two projects, but also for being a travel guide on several conferences and for sharing office with me and discussing big and small questions every day. Even though I am a bit unsocial with my headphones on, we have had the best office! Thank you also to Shahrzad

Bahrampour for working with me on the last project and for being such a positive person. To the other students: Johannes and Behzad, for always being willing to discuss and help with whatever I ask. My time pushing flies and dissecting would not have been the same without all of you around. Also a special thanks to the "lab moms" Carolin, Annika, Helen and Anna for taking care of everything around, and for caring for us students. To Ryan for working together on the first project, but also for helping me a lot in the beginning. Nacho, especially for revolutionizing the data work $:$ : Thank you Josefin for nice chats and your care.

A big thank you to the rest of Floor 13, who have contributed to the nice environment with lunch discussions, fika breaks and help when needed.

Thank you to friends for showing interest in what I am doing, but most for giving me other things to think about. I have not been the most social person during this time, but you still keep in touch and encourage me and for that I am so thankful. Especially thank you to the "Askeby team" Jannike, Cecilia and Sara: you have supported me through many years. I am so fortunate to have friends like you. You know what we say: no matter what.

Tack till mormor och morfar för att ni frågar vad det egentligen är jag gör och vad det ska vara bra för, och för god mat och fika under tiden.

To my family: you have always supported me and believed that I can do whatever I want to. Thank you for all the support and help, and for pushing me when I needed it. Mamma och 
pappa, tack för att ni har stöttat mig, trott på mig, uppmuntrat, hjälpt mig, varit hundvakt och för att jag alltid kan ringa och prata av mig. Jag vet inte hur jag ska kunna tacka er nog. Lisa och Karin, tack för att ni är stöttande, lite galna och alltid kan få mig att skratta. Trots att jag har varit lite förvirrad och glömsk har ni ändå alltid varit stöttande och positiva, och jag är så glad att just ni är mina systrar.

Alice, tack min lockiga följeslagare för att du har fått mig att tänka på annat och gett mig välbehövliga promenader.

Isak, jag är så oerhört glad att du finns. Tack för alltifrån att försöka hjälpa till med allt du kan till att köra ut mig i skogen och ge mig en kopp kaffe. Utan dig hade det här varit mycket svårare, och framför allt inte lika roligt.

Thank you all!

Erika Gunnar

December 2016 


\section{Papers}

The articles associated with this thesis have been removed for copyright reasons. For more details about these see:

http://urn.kb.se/resolve?urn=urn:nbn:se:liu:diva-133498 